\title{
How Market Sentiment Drives Forecasts of Stock Returns
}

\section{Roman Frydman, ${ }^{*}$ Nicholas Mangee ${ }^{* *}$ and Josh Stillwagon***}

\author{
Working Paper No. 115
}

April 21 ${ }^{\text {st }}, 2019$

\begin{abstract}
We reveal a novel channel through which market participants' sentiment influences how they forecast stock returns: their optimism (pessimism) affects the weights they assign to fundamentals. Our analysis yields four main findings. First, if good (bad) "news" about dividends and interest rates coincides with participants' optimism (pessimism), the news about these fundamentals has a significant effect on participants' forecasts of future returns and has the expected signs (positive for dividends and negative for interest rates). Second, in models without interactions, or when market sentiment is neutral or conflicts with news about dividends and/or interest rates, this news often does not have a significant effect on ex ante or ex post returns. Third, market sentiment is largely unrelated to the state of economic activity, indicating that it is driven by non-fundamental considerations. Moreover, market sentiment influences stock returns highly irregularly, in terms of both timing and magnitude. This finding supports recent theoretical approaches recognizing that economists and market participants alike face Knightian uncertainty about the correct model driving stock returns.
\end{abstract}

\section{https://doi.org/10.36687/inetwp115}

\footnotetext{
* Department of Economics, New York University, email: roman.frydman@nyu.edu

** Department of Finance, Parker College of Business, Georgia Southern University, email: nmangee@georgiasouthern.edu.

*** Economics Division, Babson College, email: jstillwagon@babson.edu
} 
JEL Codes: G12; G14; G41; C58

Keywords: stock-return forecasts, fundamentals, market sentiment, structural change, model ambiguity.

Acknowledgements: The authors are participants in the Program on Knightian Uncertainty Economics at the Institute for New Economic Thinking (INET). The authors are grateful to INET for continuing support of this research. 


\section{Introduction}

Models relying on the Rational Expectations Hypothesis (REH) assume that stock returns are driven solely by fundamentals, such as dividends and interest rates. These studies have frequently encountered difficulty in explaining lower-frequency returns. ${ }^{1}$ Motivated by the behavioral-finance approach, a number of recent studies have shown that, in addition to fundamentals, ex post returns are driven by market sentiment. ${ }^{2}$ However, the literature has not examined how market sentiment influences participants' (ex ante) forecasts of returns. This paper uncovers a novel channel through which sentiment influences these forecasts: switches between market participants' optimism and pessimism lead to revisions in how they relate their forecasts of stock returns to fundamentals.

We follow Greenwood and Shleifer (2014) in using survey data to proxy market participants' forecasts of stock returns. We use a proxy based on the Investor Intelligence Newsletter (IIN), which is the longest available sample of participants' forecasts. ${ }^{3}$

Our sentiment proxy is extracted from the Wall Street Journal's "Abreast of the Market" reports on daily stock-price behavior over the 30-year period from 1984-2014. ${ }^{4}$ Several previous studies have found that sentiment measures based on financial reporting contain predictive power for stock returns and fundamentals. 5

\footnotetext{
${ }^{1}$ For seminal studies documenting REH models' difficulties in accounting for the role of fundamentals in explaining lower-frequency returns, see Shiller (1981) and Mehra and Prescott (1985). For more recent studies on these models' empirical difficulties see, for example, Welch and Goyal (2008) and Ang and Bekaert (2006).

${ }^{2}$ For examples of such studies of the U.S. stock market, see Baker and Wugler (2006), Tetlock (2007), Garcia (2013), Mangee (2017), and references therein.

${ }^{3}$ Greenwood and Shleifer use seven proxies summarizing different surveys of investors' forecasts. An important contribution of their paper is to show that these proxies are highly correlated with market participants' decisions to invest their capital in mutual funds. Furthermore, Greenwood and Shleifer show that the seven proxies co-move strongly and positively, even though the surveys that underpin them rely on very different methodologies. This consistency buttresses their argument that survey evidence is not just "meaningless noise" (p. 715).

${ }^{4}$ Daily Wall Street Journal "Abreast of the Market" reports were collected through the Proquest textual data retrieval system. Our measure for market sentiment relies on the dictionary of words indicating positive and negative sentiment developed by Loughran and MacDonald (2011).

${ }^{5}$ Tetlock et al. (2008) find that this is particularly true if the news articles reference fundamentals. Garcia (2013) meanwhile finds that most of sentiment's predictive power is concentrated during recessions. These are suggestive of the interactions and asymmetries we examine more explicitly in
} 
Narrative accounts such as these offer rich and nuanced information capturing the effect that observable and unobservable factors have on investor forecasts. Akerlof and Snower (2015) and Shiller $(2017,2019)$ have recently emphasized the importance of studying the "dynamics of popular narratives, the stories, particularly those of human interest and emotion [sentiment], and how these change through time, to understand economic fluctuations," such as asset-price movements (Shiller 2017, p. 967).

Testing whether sentiment affects how fundamentals influence forecasts of returns poses two empirical difficulties. The first concerns the measurement of fundamentals themselves. Basic financial theory suggests that it is the "news" which should drive returns, since predictable trends should already be priced into forwardlooking asset markets. Indeed, a number of studies have found that "news" about fundamentals elicits a stock-price reaction; however, these studies are typically conducted with high-frequency data and use consensus forecasts to measure the news. ${ }^{6}$ With lower-frequency data, measuring news becomes more problematic. While interest-rate changes seem to be a sufficient approximation of the relevant fundamental, dividends undergo a longer-run trend.

We construct two alternative proxies for dividend news. One measures this news with a deviation of dividend growth from its sample mean. Of course, one might expect some variation in the expected dividend growth rate over time. ${ }^{7}$ To allow for this variation, we also estimate the news relative to its time-varying trend by using a procedure called step indicator saturation (Castle et al., 2015). We proxy the positive (negative) dividend news with a positive (negative) deviation of dividend growth relative to its econometrically determined time-varying trend.

The second empirical difficulty in testing our hypothesis that sentiment influences the weight of fundamentals in the specification of stock returns is that there is no a priori rationale for classifying sentiment above (below) some threshold level as relatively optimistic (pessimistic). We therefore estimate the models using various this paper.

${ }^{6}$ For examples of such studies, see Andersen et al. (2007) and Pearce and Roley (1985).

${ }^{7}$ Barsky and De Long (1993) were among the first studies to suggest that in explaining stockprice fluctuations, the dividend growth rate is better approximated as non-stationary rather than assuming that it is mean-constant. 
thresholds for optimism and pessimism. The thresholds for optimism (pessimism) were chosen as being in the top (bottom) 15th, 25th, or 40th percentile of our proxy for market sentiment. ${ }^{8}$

Our analysis yields four main findings. First, if good (bad) "news" about dividends and interest rates coincides with participants' optimism (pessimism), the news about these fundamentals has a significant effect on participants' forecasts of future returns and has the expected signs (positive for dividends and negative for interest rates). ${ }^{9}$ Second, in models without interactions, or when market sentiment is neutral or conflicts with news about dividends and/or interest rates, this news often does not have a significant effect on ex ante or ex post returns. Third, market sentiment is largely unrelated to the state of economic activity, indicating that it captures non-fundamental considerations. Moreover, market sentiment influences stock returns highly irregularly, in terms of both timing and magnitude.

There is a potential concern that our results suffer from endogeneity bias. For example, it is possible that the Fed is reducing interest rates in response to stockmarket crashes, or that sentiment is driven by recent stock returns. We address this by estimating models in which only lagged values of the regressors are included as instruments. In these specifications, we do find significant effects for the interest rate, even when sentiment does not coincide. However, we still obtain significant effects for the interaction between sentiment and both interest rates and dividends.

Addressing this potential endogeneity further, we follow Baker and Wurgler (2006) and Hilliard, Narayanasamy, and Zhang (2019). We "orthogonalize" sentiment to overall economic activity, which we proxy with the monthly growth rate of industrial production. The orthogonalized sentiment measure is the residual series from a regression of the WSJ sentiment proxy on an AR(2) specification of industrial-production growth. We show that our results are robust to using the orthogonalized sentiment measure.

These results are consistent with the finding by Hilliard, Jehra, and Zhang (2019) that the state of the economy influences the effect of dividends on stock re-

\footnotetext{
${ }^{8}$ These three threshold levels and two measures of dividend news yield six alternative specifications of stock returns.

${ }^{9}$ Mian and Sankaraguruswamy (2012) finds that sentiment impacts the announcement effect of firm-specific earnings.
} 
turns. However, the robustness of our results to using the orthogonalized sentiment measure indicates that market sentiment captures the effect of non-fundamental considerations. As Shiller (2019) and Akerlof and Snower (2016) argued, textual analysis of market narratives is an important tool in proxying such considerations.

Our findings that market sentiment influences how participants forecast returns is inconsistent with models that rely on the rational expectations hypothesis (REH) to represent these forecasts. A key feature of any REH model of stock returns is that it relates participants' forecasts of returns solely to fundamentals.

Our findings are supportive of the core premise of the behavioral-finance approach: non-fundamental factors, such as market sentiment, exert a significant influence on participants' forecasts and thus on returns. However, the behavioralfinance approach formalizes this premise with models that represent with a stochastic process how market outcomes, such as stock returns, unfold over time and how participants forecast these returns. An overwhelming majority of these models constrain their parameters - the set of variables that they include, their coefficients, and the moments of the allowed-for stochastic innovations - to be unchanging over time. Whenever these models recognize that the process underpinning outcomes undergoes change, they represent such change with a probabilistic rule, such as Markov switching, specifying ex ante how the model's specifications unfold over time. $^{10}$

Results from our analysis of structural change suggest that the relationship among stock returns, fundamentals, and sentiment is highly erratic. Modeling how such frequent shifts unfold over time presents numerous challenges for any researcher, particularly those who rely on stochastic representations of change. Indeed, we find that the high degree of irregular structural change reflected in interactions between sentiment and fundamentals is undetectable with standard tests for parameter instability, such as the Chow breakpoint test. These results suggest that models recognizing that the process driving outcomes undergoes change that cannot be represented with a stochastic process might offer a way to understand how

\footnotetext{
${ }^{10}$ For an influential contribution to the development of models that represent change with probabilistic rules, and an authoritative recent review, see Hamilton (1988, 2008). For a seminal behavioral-finance model that formalizes with a stochastic process the role of market sentiment in how participants forecast returns, see Barberis et al. (1998).
} 
both fundamental and non-fundamental factors influence returns. In the Concluding Remarks, we highlight earlier studies documenting difficulties inherent in specifying change in asset returns and macroeconomic outcomes with a probabilistic rule, such as Markov switching, ex ante.

The structure of the paper is as follows: Section 2 describes the data and the proxies for market sentiment, participants' forecasts of stock returns, and the dividend and interest-rate news used in our analysis. Section 3 discusses the empirical specification and presents our main hypotheses in terms of the restrictions on this specification. Section 4 presents the empirical findings regarding these hypotheses. Section 5 provides econometric evidence that the influence of market sentiment on how participants forecast returns is highly irregular, thereby causing frequent structural breaks in the relationship between forecasted (as well as realized) stock returns and news on dividends and interest rates. Section 6 places the findings of this paper in the context of earlier empirical studies documenting structural change in the process driving outcomes. We also point out that recognizing the relevance of change that cannot be represented ex ante with probabilistic rules in a theoretical model uncovers a novel channel through which market sentiment influences stock returns.

\section{Data and Variables}

Here, we define the data and variables used in our empirical analysis. First, we describe the survey measure for participants' forecasts of returns. Second, we discuss how we measure the news on dividends and interest rates. Finally, we introduce our proxy for sentiment extracted from the WSJ reports and define interactive dummies that represent how market sentiment influences the weights that participants attach to news about fundamentals.

\subsection{Participants' Forecasts of Returns}

We use a proxy for market participants' forecasts of returns that summarizes the survey by the Investors Intelligence Newsletter (IIN), which is the longest survey among those studied by Greenwood and Shleifer (2014). The IIN survey records the percentage of its participants' bullish, neutral, and bearish forecasts on a weekly 
basis. Given that most of the other variables are measured at monthly intervals, we use a monthly average. Moreover, we denote by $\widehat{R}_{t+12 \mid t}$ the participants' time-t forecast of stock returns over the succeeding 12-month period, $t+12$. Following Greenwood and Shleifer, we proxy $\widehat{R}_{t+12 \mid t}$ with the difference between the proportion of market participants who are bullish and bearish at $t$ concerning stock prices at $t+12$ :

$$
\widehat{R}_{t+12 \mid t}=\left[\% \text { bullish }_{t}-\% \text { bearish }_{t}\right]
$$

Measures computed according to (1) do not yield numerical observations of price changes expected by survey participants. However, Greenwood and Shleifer show that such proxies are highly correlated with the shorter sample available from Gallup surveys, which provide numerical forecasts of stock returns from September 1998 through May 2003.

\subsection{Ex Post Stock Returns, Dividends, and Interest Rates}

Data on ex post returns and index of dividends are from Robert Shiller's homepage, while interest-rate data are collected from the Board of Governors' H.15 release. ${ }^{11}$ Aggregate log-dividends correspond to the S\&P 500, and interest rates are the oneyear Treasury bill constant maturity rate. In order to address the problems posed by non-stationarity in dividends and interest rates, both series are first-differenced. ${ }^{12}$

\subsection{Alternative Measures of Dividend News}

We construct two proxies for dividend news. First, because dividends have undergone a long-term trend of typically positive growth, we de-mean the first-differenced dividend series to capture "news" about whether dividend growth is above or below average. Second, we proxy dividend news relative to a time-varying mean growth rate. The varying mean growth rate is estimated using the step indicator saturation (SIS) procedure developed by Hendry, Johansen, and Santos (2008). This procedure includes a step indicator for each observation that is equal to one from the first

\footnotetext{
${ }^{11}$ The historical dataset can be found at http://www.econ.yale.edu/ shiller/data.htm.

${ }^{12}$ For a detailed examination of the problems posed by the non-stationarity of fundamental variables in specifying stock returns, see Frydman and Stillwagon (2018).
} 
observation up until time $t$, and equal to zero thereafter. The indicators for each observation allow the mean to vary at any point in time. The significant changes in mean are then selected through the Autometrics tree search algorithm (Doornik, 2009).

In this application, we select the significant breaks at a very stringent level of $0.01 \%$, meaning that only one in 10,000 would be erroneously included. This errs on the side of missing smaller variations in the expected growth rate, in order to avoid overfitting (in the extreme case, very little would be classified as news) and to allow for some change in the rate of dividend growth, as opposed to assuming a constant rate at the sample average. Figure 1 documents the fluctuations in the mean rate of dividend growth as deduced by SIS. 
Figure 1: The Estimated Mean Growth in Log-Dividends based on Step Indicator Saturation

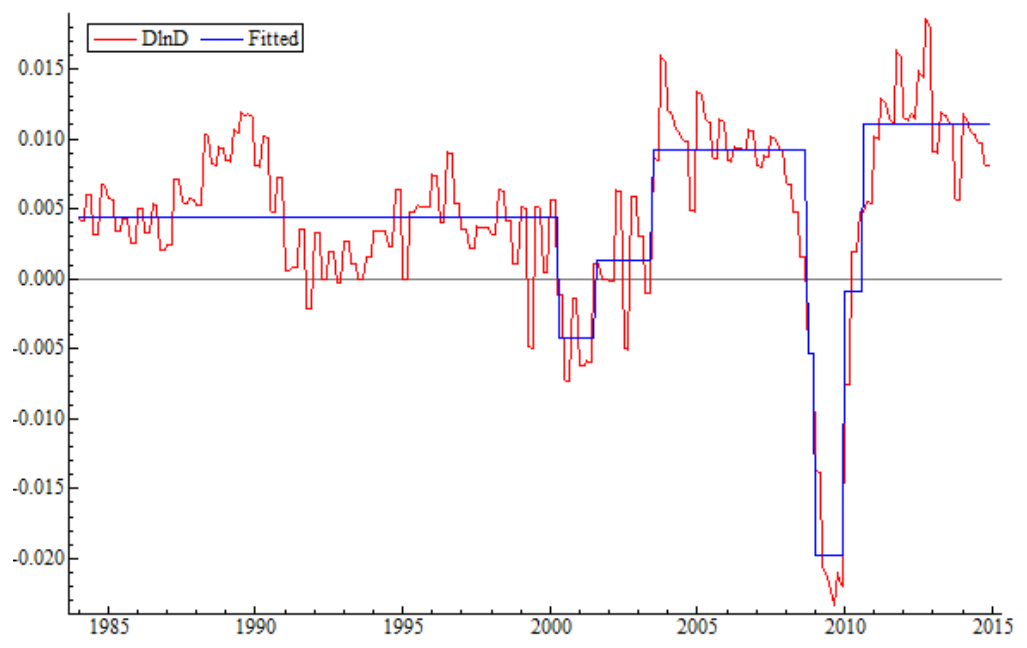

Figure 1 shows that the mean growth rate is constant from the beginning of the sample until 2000, or at least the fluctuations are not significant at $0.01 \%$. It then declines, rises gradually in the mid-2000s, and then plummets with the financial crisis, rising again thereafter. We estimate all of the models measuring dividend news relative to this varying mean. In other words, when log-dividend growth (in red in Figure 1) is above the expected growth rate based on SIS (in blue), the dividend news would be classified as positive. Conversely, when dividend growth is below the expected growth rate based on SIS, the dividend news would be deemed negative. 


\subsection{Market Sentiment}

We draw on a growing body of research that focuses on a connection between stock-market outcomes and investor sentiment as measured by narrative information contained in financial-market reporting. Like Tetlock (2007) and others, we measure sentiment by the tone of optimism/pessimism from daily Wall Street Journal "Abreast of the Market" summaries. Moreover, in measuring the tone of such reports, we follow Garcia (2013) and others by using Loughran and McDonald's (2011) finance-specific classification dictionary. The LM dictionary has been shown to provide a better representation of contextualized information from summary market reports specific to the finance industry (Mangee, 2019). We express our sentiment measure as:

$$
\text { Sent }_{t}=(P-N) /(P+N+1)
$$

where $\mathrm{N}$ and $\mathrm{P}$ are the total number of negative and positive words each month, respectively, based on the LM classification dictionary. ${ }^{13}$

\subsubsection{Optimistic, Pessimistic, and Neutral Market Sentiment}

Because our sentiment measure takes on strictly negative values (the negative word count always exceeds the positive word count), we create dummy variables, based on whether the sentiment measure exceeds various thresholds, to define relative optimism and pessimism. In our analysis, we check the robustness of our findings by using values for the $n^{\text {th }}$ percentile of 15,25 , and 40 .

The first dummy variable, $S_{t}^{+}$, represents relative optimism: $S_{t}^{+}=1$, if sentiment exceeds the top $n^{\text {th }}$ percentile threshold (e.g., if $S e n t_{t}$ in (2) exceeds the 85th percentile), otherwise $S_{t}^{+}=0$. Analogously, $S_{t}^{-}$represents relative pessimism: $S_{t}^{-}=1$, if sentiment is in the bottom $n^{\text {th }}$ percentile threshold (e.g., if $S e n t_{t}$ in (2) is below the $15 t h$ percentile), otherwise $S_{t}^{-}=0$. We refer to market sentiment as neutral if $S_{t}^{+}=0$ and $S_{t}^{-}=0$.

\footnotetext{
${ }^{13}$ We use the TextMining (TM) package available in R, which is based on the vector space method. The general results are robust to other normalizations, for example dividing by total word count or using only the unique positive and negative words each month.
} 


\subsection{Interaction Terms}

In order to allow for a differential effect of fundamentals when they coincide with sentiment, we also need to specify dummy variables for whether the news is positive or negative. To this end, we denote the dividend news by $\Delta d_{t}^{d m}$ and represent good (bad) news with $\Delta d_{t}^{d m}>0\left(\Delta d_{t}^{d m}<0\right)$. (i.e., dividend growth is above (below) its constant or time-varying mean). Analogously, we refer to news about interest rates as good (bad) if interest rates fall (rise), that is, $\Delta i_{t}<0\left(\Delta i_{t}>0\right)$. We then define the following dummy variables, representing interactions between the effects of dividends and market sentiment:

$$
\begin{aligned}
& D S_{t}^{+}=1, \text { if } \Delta d_{t}^{d m}>0 \text { and } S_{t}^{+}=1, \\
& D S_{t}^{-}=1, \text { if } \Delta d_{t}^{d m}<0 \text { and } S_{t}^{-}=1, \\
& I S_{t}^{+}=1, \text { if } \Delta i_{t}<0 \text { and } S_{t}^{+}=1 \\
& I S_{t}^{-}=1, \text { if } \Delta i_{t}>0 \text { and } S_{t}^{-}=1
\end{aligned}
$$

Figures 2 and 3 illustrate how these dummies interact with news about fundamentals. Figure 2 portrays $\Delta d_{t}^{d m} \cdot D S_{t}^{+}$and $\Delta d_{t}^{d m} \cdot D S_{t}^{-}$for the 40th percentile threshold. The variable $\Delta d_{t}^{d m} \cdot D S_{t}^{+}$, in red, takes on the strictly positive values of $\Delta d_{t}^{d m}$, but only during the periods when sentiment is also optimistic. Otherwise, it is equal to zero. During some of the periods in which market sentiment is not relatively optimistic, $\Delta d_{t}^{d m} \cdot D S_{t}^{-}$, in blue, takes on the strictly negative values of $\Delta d_{t}^{d m}$, but only when sentiment is also pessimistic. During the periods within which market sentiment is neutral (neither optimistic nor pessimistic) or conflicts with the news about fundamentals, both $\Delta d_{t}^{d m} \cdot D S_{t}^{+}$and $\Delta d_{t}^{d m} \cdot D S_{t}^{-}=0$. 
Figure 2: Dividends interacted with a 40th percentile threshold for optimism and pessimism

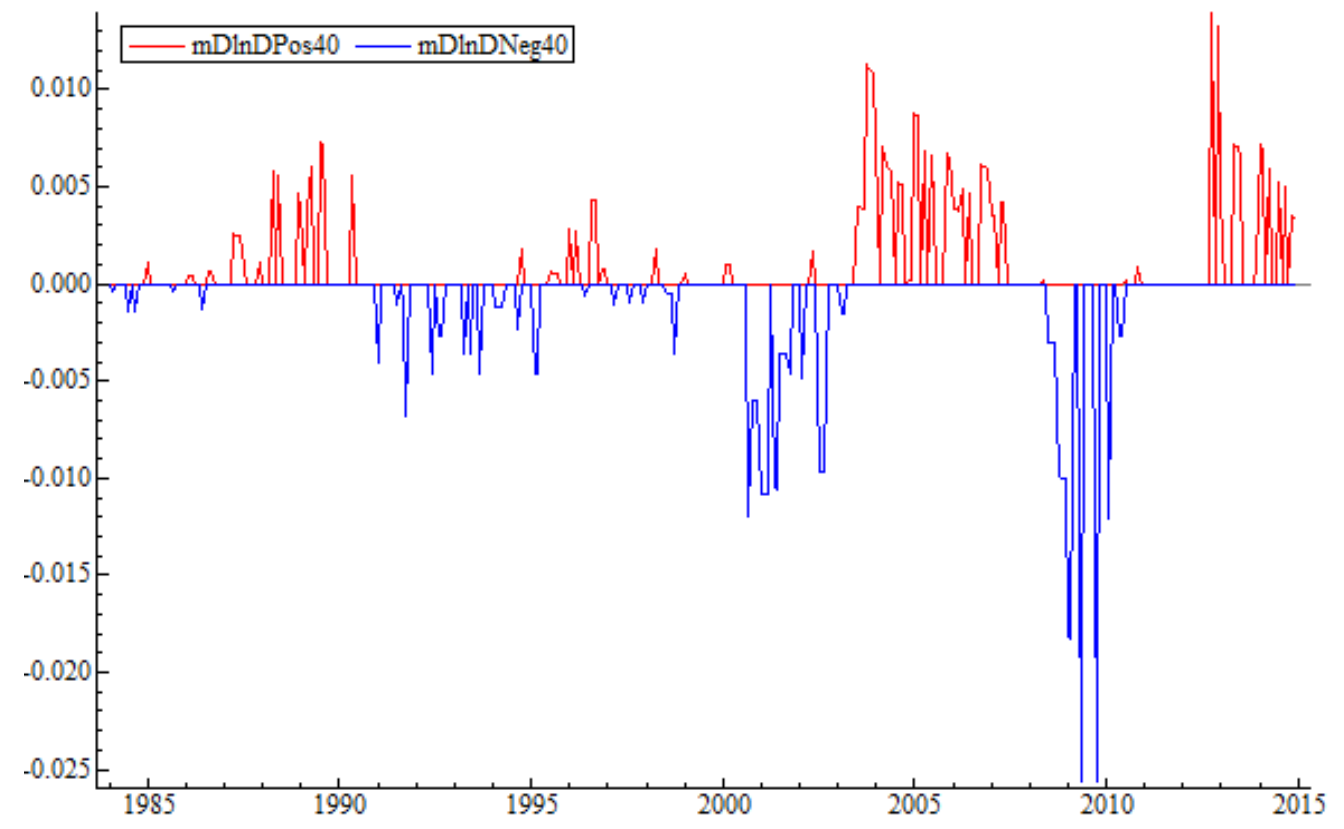


Analogously, Figure 3 shows both $\Delta i_{t} \cdot I S_{t}^{+}$, in red, and $\Delta i_{t} \cdot I S_{t}^{-}$, in blue, which represent the decreases (increases) in the interest rate when sentiment is also in the upper (lower) 40th percentile.

Figure 3: Interest rates interacted with a 40th percentile threshold for optimism and pessimism

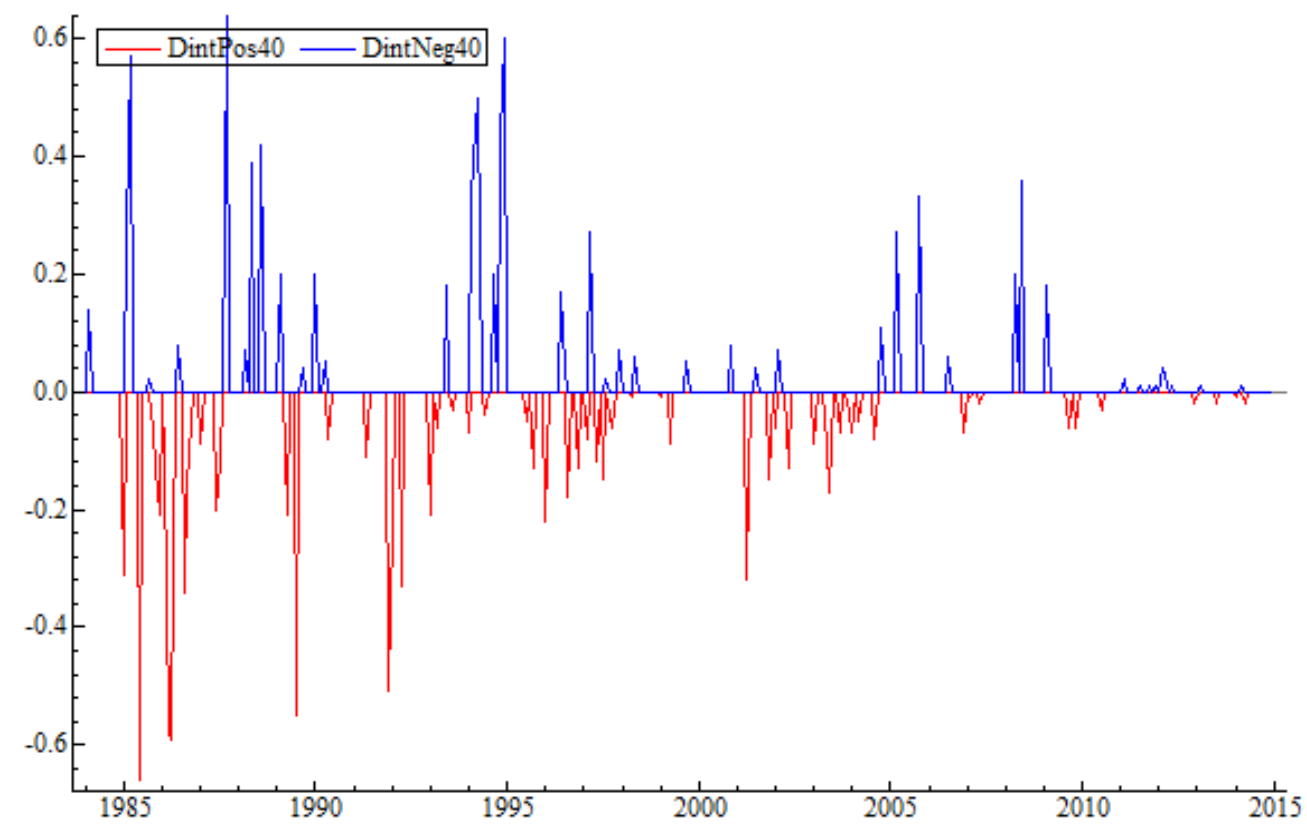

\section{Model Specifications}

We specify an empirical model for both the market's forecast and ex post stock returns, which we denote by $\widehat{R}_{t+12 \mid t}$ in (1) and $R_{t \mid t-1}$, respectively. We find that forecasted $\left(\widehat{R}_{t+12 \mid t}\right)$, ex post $\left(R_{t \mid t-1}\right)$ return series, and the sentiment proxy in (2) do not contain a unit root. However, the log-dividends (d) and interest rates (i) are found to be difference-stationary. ${ }^{14}$ Consequently, we first-difference dividends and

\footnotetext{
${ }^{14}$ Conventional ADF unit-root tests with auto-selected lag-length for $\widehat{R}_{t}, R_{t}, \Delta d_{t}, \Delta i_{t}$ and $s_{t}$ generate t-statistics(p-values) of -6.04(.000), -14.703(.000), -2.893(.047), -8.283(.000), and -
} 
interest rates, which permits the use of Ordinary Least Squares (OLS) for estimation of the two sets of regression models. We consider the following framework for forecasted and realized returns:

$$
\begin{aligned}
\Omega_{t}= & \beta_{1}+\beta_{2} \Omega_{t-1}+\beta_{3} \Omega_{t-2}+\beta_{4} \Delta d_{t}^{d m}+\beta_{5} \Delta i_{t}+\beta_{6} \Delta d_{t}^{d m} \cdot D S_{t}^{+}+ \\
& \beta_{7} \Delta d_{t}^{d m} \cdot D S_{t}^{-}+\beta_{8} \Delta i_{t} \cdot I S_{t}^{+}+\beta_{9} \Delta i_{t} \cdot I S_{t}^{-}+\epsilon_{t}
\end{aligned}
$$

where $\Omega_{t}$ is either $\widehat{R}_{t+12 \mid t}$ or $R_{t \mid t-1}$. As mentioned previously, $\Delta i_{t}$ is the differenced one-month interest rate. $\Delta d_{t}^{d m}$ is the dividend news, more specifically measured as the growth rate after de-meaning, to capture whether dividend growth is above or below average (expected). $\left(D S_{t}^{+}, D S_{t}^{-}, I S_{t}^{+}, I S_{t}^{-}\right)$is a vector of (interactive) dummy variables defined in (3)-(6).

\subsection{Hypotheses}

In the model for both forecasted and realized returns, the coefficients $\beta_{4}$ and $\beta_{5}$ represent the effects of news when sentiment is either neutral or conflicting. The coefficients for the interaction terms ( $\beta_{6}$ through $\beta_{9}$ ), capture the differential effects when sentiment and the news coincide (e.g. good news and optimism). We consider the following hypotheses:

Hypothesis 1A: $\beta_{6}>0$, i.e., optimistic sentiment leads market participants to attach a higher positive weight to positive dividend news than they would attach to such news when the sentiment is pessimistic or neutral.

Analogously,

Hypothesis 1B: then $\beta_{7}>0$.

Hypothesis $2 \mathrm{~A}$ : then $\beta_{8}<0$.

Hypothesis $2 \mathrm{~B}$ : then $\beta_{9}<0$.

6.654(.000), respectively. 


\section{Results}

Table 1: Forecasts of returns with mean dividend growth

\begin{tabular}{|c|c|c|c|c|}
\hline Percentile & & 15 th & 25 th & 40th \\
\hline cons. & $\begin{array}{l}3.041 \\
{[4.26]}\end{array}$ & $\begin{array}{l}3.659 \\
{[4.70]}\end{array}$ & $\begin{array}{l}3.458 \\
{[4.49]}\end{array}$ & $\begin{array}{l}3.759 \\
{[4.85]}\end{array}$ \\
\hline $\operatorname{AR}(1)$ & $\begin{array}{l}0.891 \\
{[19.02]}\end{array}$ & $\begin{array}{l}0.880 \\
{[17.69]}\end{array}$ & $\begin{array}{l}0.881 \\
{[17.84]}\end{array}$ & $\begin{array}{l}0.870 \\
{[17.42]}\end{array}$ \\
\hline $\operatorname{AR}(2)$ & $\begin{array}{c}-0.085 \\
{[-1.84]}\end{array}$ & $\begin{array}{c}-0.098 \\
{[-2.10]}\end{array}$ & $\begin{array}{c}-0.095 \\
{[-2.00]}\end{array}$ & $\begin{array}{c}-0.102 \\
{[-2.26]}\end{array}$ \\
\hline$\Delta d_{t}^{d m}$ & $\begin{array}{c}-11.393 \\
{[-0.20]}\end{array}$ & $\begin{array}{c}-37.662 \\
{[-0.66]}\end{array}$ & $\begin{array}{c}-29.655 \\
{[-0.46]}\end{array}$ & $\begin{array}{c}-44.028 \\
{[-0.79]}\end{array}$ \\
\hline$\Delta i_{t}$ & $\begin{array}{c}-1.597 \\
{[-0.70]}\end{array}$ & $\begin{array}{l}-1.020 \\
{[-0.387]}\end{array}$ & $\begin{array}{c}-0.056 \\
{[-0.02]}\end{array}$ & $\begin{array}{c}2.963 \\
{[1.04]}\end{array}$ \\
\hline$\Delta d_{t}^{d m} \cdot S_{t}^{+}$ & & $\begin{array}{c}406.241 \\
{[1.79]}\end{array}$ & $\begin{array}{c}479.560 \\
{[2.42]}\end{array}$ & $\begin{array}{c}423.33 \\
{[2.54]}\end{array}$ \\
\hline$\Delta d_{t}^{d m} \cdot S_{t}^{-}$ & & $\begin{array}{c}990.433 \\
{[2.18]}\end{array}$ & $\begin{array}{c}78.369 \\
{[0.49]}\end{array}$ & 204.111 \\
\hline$\Delta i_{t} \cdot S_{t}^{+}$ & & $\begin{array}{c}-4.395 \\
{[-0.67]}\end{array}$ & $\begin{array}{c}-1.594 \\
{[-0.27]}\end{array}$ & $\begin{array}{c}-11.243 \\
{[-2.32]}\end{array}$ \\
\hline$\Delta i_{t} \cdot S_{t}^{-}$ & & -18.124 & $\begin{array}{c}-16.242 \\
{[-3.07]}\end{array}$ & $\begin{array}{c}-20.964 \\
{[-3.75]}\end{array}$ \\
\hline Adj. $\mathrm{R}^{2}$ & 0.671 & 0.679 & 0.676 & 0.687 \\
\hline
\end{tabular}

Caption: Newey-West heteroskedasticity and auto-correlation (HAC) robust tvalues are displayed in brackets underneath the coefficient estimates.

We first estimate the survey data model without interactions. The results are presented in the first column in Table 1, which shows that interest rates and dividends are highly insignificant. Columns 2-4 present the models with interaction terms between sentiment and fundamental news, for alternative thresholds of sentiment $\left(15^{\text {th }}, 25^{\text {th }}\right.$, and $40^{\text {th }}$ percentiles, respectively). For the general dividend and interest-rate effects (i.e., when sentiment is conflicting or neutral) the coefficient is statistically insignificant. Even in the models with interactions, we find that fundamentals have no significant effect when the news does not align with sentiment.

By contrast, we find many significant effects for both dividend and interest-rate news, reported in columns $2-4$, when these are interacted with sentiment. Moreover, across the three models with alternative threshold levels for relative optimism (pessimism), we find evidence in support of each of the individual hypotheses, 1A: $\beta_{6}>0,1 \mathrm{~B}: \beta_{7}>0,2 \mathrm{~A}: \beta_{8}<0$ and $2 \mathrm{~B}: \beta_{9}<0$. When there is negative 
news about interest rates and market sentiment is pessimistic, participants forecast lower stock returns. This effect is significant at the $1 \%$ level in all three models. Similarly, hypothesis 1A finds support across the three models. Dividends have a positive effect on stock-return forecasts when there is good news (i.e., dividend growth is above the mean) and sentiment is optimistic. This is significant at $10 \%$ in the $15^{\text {th }}$-percentile model, and at $5 \%$ in the other two models.

In some models, we also find significant effects for the interactions when adverse dividend news aligns with pessimism, or interest-rate reductions coincide with optimism. In the model with the $15^{t h}$-percentile threshold, the negative dividend news (i.e., below-mean growth), when accompanied by pessimistic sentiment leads participants to lower their forecasts of stock returns. In the model with the $40^{\text {th }}$-percentile threshold, we find a significant effect when good news regarding interest-rate news coincides with participants' optimism.

The magnitudes of the interactions in any given specification do appear to depend on the selected threshold. This suggests that different thresholds are relevant for different types of news, and that combining models with different threshold levels for different types of news may be fruitful. However, although precise estimates differ across thresholds and time, our results provide support for the hypothesis that market sentiment affects participants' forecasts through its interaction with the news about fundamentals.

We also find evidence of strong persistence to forecasts of returns, as is evident in the significance of the first lag in row 2 of Table 1. This forecast "inertia" was previously found in Frydman and Stillwagon (2018). It is also consistent with the "sticky information" of Mankiw and Reis (2002) and Coibion and Gorodnichenko (2012). While the first lag is positive and significant, the second lag is marginally significant and negative. This dynamic could be viewed as consistent with longerrun "over-reaction" which then tends to mean-revert. ${ }^{15}$

We test the sensitivity of our results using our alternative measure of dividend "news" from the SIS procedure. Table 2 reports regression estimates based on a model allowing for breaks in the mean of the dividend growth series (measured as

\footnotetext{
${ }^{15}$ De Bondt and Thaler (1985), Cutler et al. (1991), Chopra et al. (1992), Fama and French (1992), Lakonishok et al. (1994), and La Porta (1996).
} 
the log first-difference).

Table 2: Forecasts of returns with breaks in mean dividend growth

\begin{tabular}{|c|c|c|c|c|}
\hline Percentile & & 15 th & 25 th & 40th \\
\hline cons. & $\begin{array}{c}3.003 \\
{[4.23]}\end{array}$ & $\begin{array}{c}3.836 \\
{[4.87]}\end{array}$ & $\begin{array}{l}3.709 \\
{[4.79]}\end{array}$ & $\begin{array}{l}3.868 \\
{[4.94]}\end{array}$ \\
\hline $\operatorname{AR}(1)$ & $\begin{array}{l}0.890 \\
{[19.18]}\end{array}$ & $\begin{array}{l}0.878 \\
{[17.97]}\end{array}$ & $\begin{array}{l}0.880 \\
{[17.83]}\end{array}$ & $\begin{array}{l}0.866 \\
{[17.18]}\end{array}$ \\
\hline $\operatorname{AR}(2)$ & $\begin{array}{c}-0.084 \\
{[-1.85]}\end{array}$ & $\begin{array}{c}-0.103 \\
{[-2.23]}\end{array}$ & $\begin{array}{c}-0.097 \\
{[-2.12]}\end{array}$ & $\begin{array}{c}-0.091 \\
{[-2.02]}\end{array}$ \\
\hline$\Delta d_{t}^{d m}$ & $-\underset{[-1.07]}{158.281}$ & $\begin{array}{c}-305.492 \\
{[-1.97]}\end{array}$ & $\begin{array}{c}-317.114 \\
{[-1.96]}\end{array}$ & $-\frac{176.114}{[-1.15]}$ \\
\hline$\Delta i_{t}$ & $\begin{array}{c}-1.379 \\
{[-0.61]}\end{array}$ & $\begin{array}{c}-0.733 \\
{[-0.28]}\end{array}$ & $\begin{array}{c}-0.632 \\
{[-0.234]}\end{array}$ & $\begin{array}{l}4.054 \\
{[1.43]}\end{array}$ \\
\hline$\Delta d_{t}^{d m} \cdot S_{t}^{+}$ & & $\begin{array}{c}-121.468 \\
{[-0.22]}\end{array}$ & $\begin{array}{c}859.456 \\
{[2.06]}\end{array}$ & $\begin{array}{c}-154.966 \\
{[-0.362]}\end{array}$ \\
\hline$\Delta d_{t}^{d m} \cdot S_{t}^{-}$ & & $\begin{array}{c}1367.61 \\
{[2.43]}\end{array}$ & $\begin{array}{c}816.262 \\
{[2.17]}\end{array}$ & $\begin{array}{c}395.752 \\
{[1.28]}\end{array}$ \\
\hline$\Delta i_{t} \cdot S_{t}^{+}$ & & $\begin{array}{c}-5.265 \\
{[-0.79]}\end{array}$ & $\begin{array}{c}1.176 \\
{[0.19]}\end{array}$ & $-\frac{12.601}{[-2.55]}$ \\
\hline$\Delta i_{t} \cdot S_{t}^{-}$ & & $\begin{array}{c}-15.434 \\
{[-2.51]}\end{array}$ & $\begin{array}{c}-13.788 \\
{[-2.50]}\end{array}$ & $\begin{array}{c}-23.179 \\
{[-4.03]}\end{array}$ \\
\hline Adj. $R^{2}$ & 0.672 & 0.683 & 0.679 & 0.687 \\
\hline
\end{tabular}

Caption: Newey-West heteroskedasticity and auto-correlation (HAC) robust tvalues are displayed in brackets underneath the coefficient estimates.

The results are broadly similar to those reported in Table 1 . There are no significant effects with the expected sign for any of the fundamentals without interactions in any of the models of forecasted returns, irrespective of the inclusion of other interaction terms, or the threshold defining optimism or pessimism. By contrast, when interactions are incorporated, we find significant effects for any chosen threshold with the hypothesized signs for both dividends and interest-rate news. We also find evidence of expectations inertia again (the highly significant lag) and longer-run mean reversion as captured by the marginally significant second lag with a negative coefficient.

We again find support for a significant effect of negative interest-rate news when negative sentiment coincides. The positive interest-rate news interaction is significant only in the $40^{t h}$-percentile model. Both of these results are consistent with Table 1. In Table 2 however, we find a significant effect of negative dividend news 
in two of the models, and in only one for positive dividend news. This result, with dividend news now measured relative to the time-varying trend, is consistent with some evidence (e.g., Chan, 2003) that negative news on fundamental factors exerts a greater influence on returns.

\subsection{Market Sentiment as an Additional Explanatory Variable}

Previous studies of the role of sentiment in ex post returns have often included it as an additional explanatory variable separate from fundamentals (Baker and Wurgler 2006; Tetlock 2007; Garcia 2012). However, market participants' forecasts of returns reflect their sentiment regarding future outcomes; thus, both forecasted returns and sentiment are likely to be driven by similar sets of variables. Indeed, as Figure 4 shows, our proxy for participants' forecasts co-moves very closely with our measure of sentiment.

Because sentiment is essentially an expectational variable, including it in models of forecasted returns additively would capture all other effects. This is what we report in Appendix Table 4: once we add sentiment to our specifications in (1), all other variables become insignificant. Thus, allowing for additive sentiment obscures the way in which sentiment affects the weights participants attach to fundamentals in forecasting returns reported in Tables 1 and $2 .{ }^{16}$

\footnotetext{
${ }^{16}$ In models of ex post returns, even when including sentiment additively, we find effects of dividends. This is consistent with other studies on sentiment and ex post returns. See Table 7 in the Appendix.
} 
Figure 4: Survey Forecasted Returns and the Text Analysis Sentiment Measure

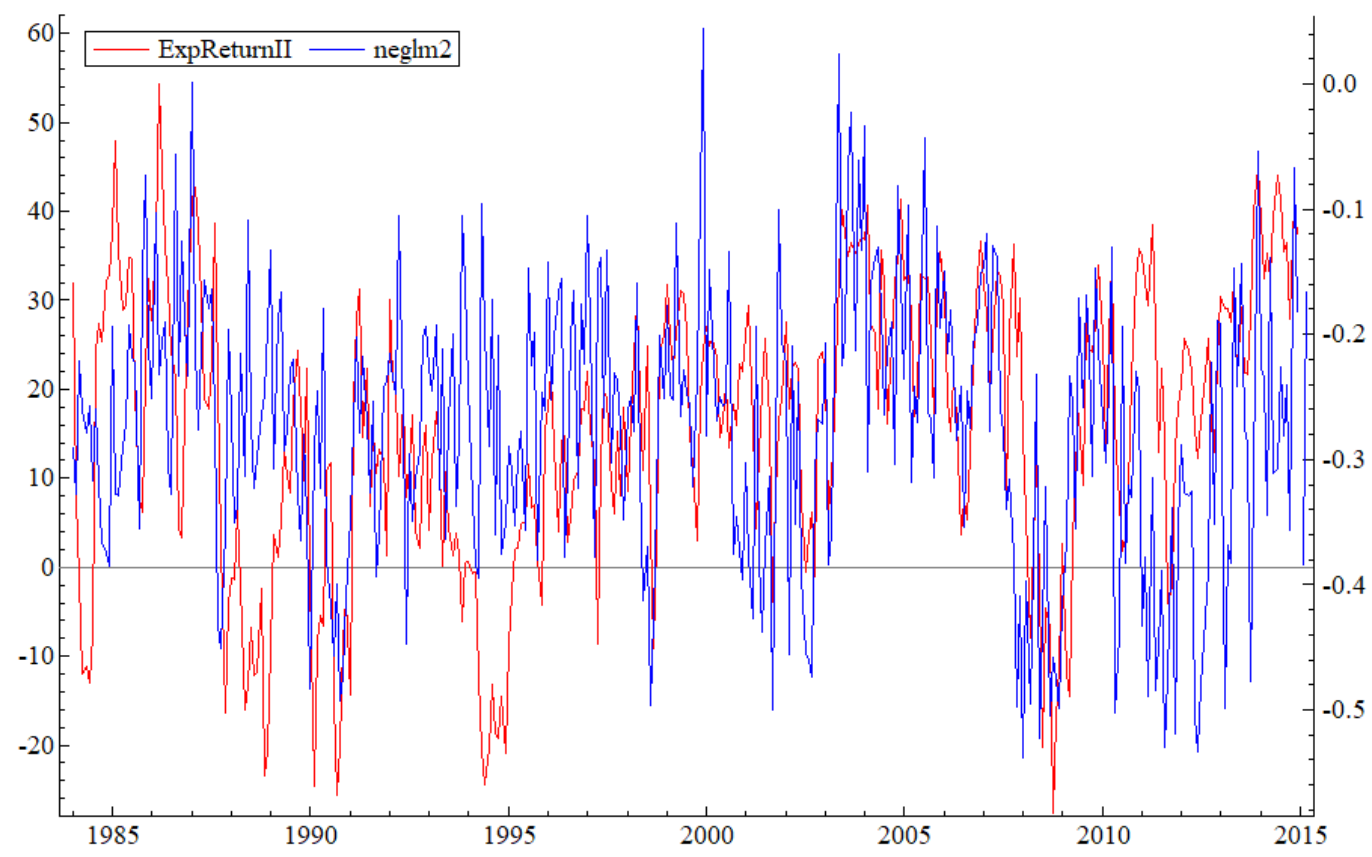




\subsection{Robustness to Instruments, Outliers, and Omitted variables}

There are two potential concerns related to the results reported above. One is endogeneity. Another is that the results could be driven by a few outliers.

Although we would typically hypothesize that optimistic sentiment about the economy causes high expected returns on stocks, it is possible that the converse is also the case. Shiller (2005), for example, has argued that high stock returns in the 1990's contributed to beliefs in a "new era IT revolution." Similarly, expected returns may influence the variables on the right-hand side of our specification. For example, an expected stock-market crash (or continuation thereof) may induce the Federal Reserve to cut interest rates. In this case, the endogeneity bias works against our typical presumption of an inverse relationship whereby interestrate cuts should boost stocks. However, it is also possible that high expected returns could encourage firms to increase dividend payouts. This positive endogeneity bias diminishes confidence in our conclusions about dividends. In order to address this, we re-estimate Table 1 using only lagged values of the regressors as instrumental variables.

Interestingly, once we use lags as instruments, the effect of interest rates during times of neutral or conflicting sentiment attain statistical significance with the hypothesized sign. This is consistent with our foregoing conjecture that the contemporaneous interest rates would have a positive endogeneity bias (because the Fed would cut rates during a stock-market crash). Moreover, we still find significant interactions for both interest rates and dividends using lags as instruments, regardless of which of the three thresholds we use to define optimism and pessimism. 
Table 3: Forecasted returns with mean dividend growth, instrumental lags, and automated adjustment for outliers and breaks

\begin{tabular}{|c|c|c|c|c|}
\hline Percentile & & 15 th & 25 th & 40th \\
\hline cons. & $\begin{array}{l}3.041 \\
{[4.26]}\end{array}$ & $\begin{array}{l}5.910 \\
{[6.44]}\end{array}$ & $\begin{array}{l}3.458 \\
{[4.49]}\end{array}$ & $\begin{array}{l}3.940 \\
{[4.94]}\end{array}$ \\
\hline $\operatorname{AR}(1)$ & $\begin{array}{l}0.860 \\
{[18.13]}\end{array}$ & $\begin{array}{l}0.789 \\
{[15.58]}\end{array}$ & $\begin{array}{l}0.782 \\
{[15.50]}\end{array}$ & $\begin{array}{l}0.839 \\
{[16.96]}\end{array}$ \\
\hline $\operatorname{AR}(2)$ & $\begin{array}{c}-0.110 \\
{[-2.31]}\end{array}$ & $\begin{array}{c}-0.081 \\
{[-1.62]}\end{array}$ & $\begin{array}{c}-0.069 \\
{[-1.39]}\end{array}$ & $\begin{array}{c}-0.090 \\
{[-1.84]}\end{array}$ \\
\hline$\Delta d_{t-1}^{d m}$ & $\begin{array}{c}42.099 \\
{[0.63]}\end{array}$ & $\begin{array}{c}-29.296 \\
{[-0.39]}\end{array}$ & $\begin{array}{c}-89.794 \\
{[-1.12]}\end{array}$ & $\begin{array}{c}-61.879 \\
{[-0.71]}\end{array}$ \\
\hline$\Delta i_{t-1}$ & $\begin{array}{l}-7.062 \\
{[-4.04]}\end{array}$ & $\begin{array}{c}-6.990 \\
{[-3.66]}\end{array}$ & $\begin{array}{c}-5.655 \\
{[-2.87]}\end{array}$ & $\begin{array}{l}-5.228 \\
{[-2.43]}\end{array}$ \\
\hline$\Delta d_{t-1}^{d m} \cdot S_{t-1}^{+}$ & & $\begin{array}{c}426.004 \\
{[1.35]}\end{array}$ & $\begin{array}{c}645.392 \\
{[2.48]}\end{array}$ & $\begin{array}{c}555.184 \\
{[2.53]}\end{array}$ \\
\hline$\Delta d_{t-1}^{d m} \cdot S_{t-1}^{-}$ & & $\begin{array}{c}715.191 \\
{[2.64]}\end{array}$ & $\begin{array}{c}455.990 \\
{[2.38]}\end{array}$ & $\begin{array}{c}227.784 \\
{[1.32]}\end{array}$ \\
\hline$\Delta i_{t-1} \cdot S_{t-1}^{+}$ & & $\begin{array}{c}-12.097 \\
{[-0.88]}\end{array}$ & $\begin{array}{c}-9.279 \\
{[-1.10]}\end{array}$ & $\begin{array}{c}-5.281 \\
{[-0.88]}\end{array}$ \\
\hline$\Delta i_{t-1} \cdot S_{t-1}^{-}$ & & -22.264 & -19.603 & $\begin{array}{c}-13.888 \\
{[-2.39]}\end{array}$ \\
\hline Adj. $\mathrm{R}^{2}$ & 0.671 & 0.711 & 0.715 & 0.719 \\
\hline
\end{tabular}

Caption: t-values are listed in brackets underneath the coefficient estimates. See appendix for further details on the included indicators for outliers and mean shifts.

As with any statistical analysis, the results could be driven by a few outliers. To control for this, all of the models in Table 3 use impulse indicator saturation (Hendry, Johansen, and Santos, 2010). This approach is analogous to the Huberskip estimator and least trimmed squares. ${ }^{17}$ The significant outliers and mean shifts are described in the Appendix. Given the inclusion of these model adjustments, the adjusted R-squareds no longer maintain their usual interpretation (because some of the variation is explained in an ad hoc fashion to control for these outliers).

With regard to outliers, the financial crisis seems like an obvious candidate. Although the indicator-saturation approach should detect this, we further reinforce the robustness of our findings by ending the estimation in 2007(11), before the NBER official beginning of the Great Recession, and in 2008(8), just before the

\footnotetext{
${ }^{17}$ The indicators or dummy variables are selected in blocks using the Autometrics tree search algorithm (Doornik, 2009). The block search produces a higher "breakdown point" and much greater robustness to outliers compared to OLS or alternatives like the least absolute deviation estimator.
} 
collapse of Lehman Brothers. The results are robust in both cases, and the former estimates are displayed in Table 8 of the Appendix.

\subsection{Sentiment as a Proxy for Non-Fundamental Considerations}

Hilliard, Jahera, and Zhang (2019) document that the effect of changes to dividend policy depends on the state of the economy. Figures 5 and 6 replicate Figures 2 and 3 , but now with the NBER recession dates shaded in yellow.

Figure 5: Recession dates and dividends interacted with a 40th percentile threshold for optimism and pessimism

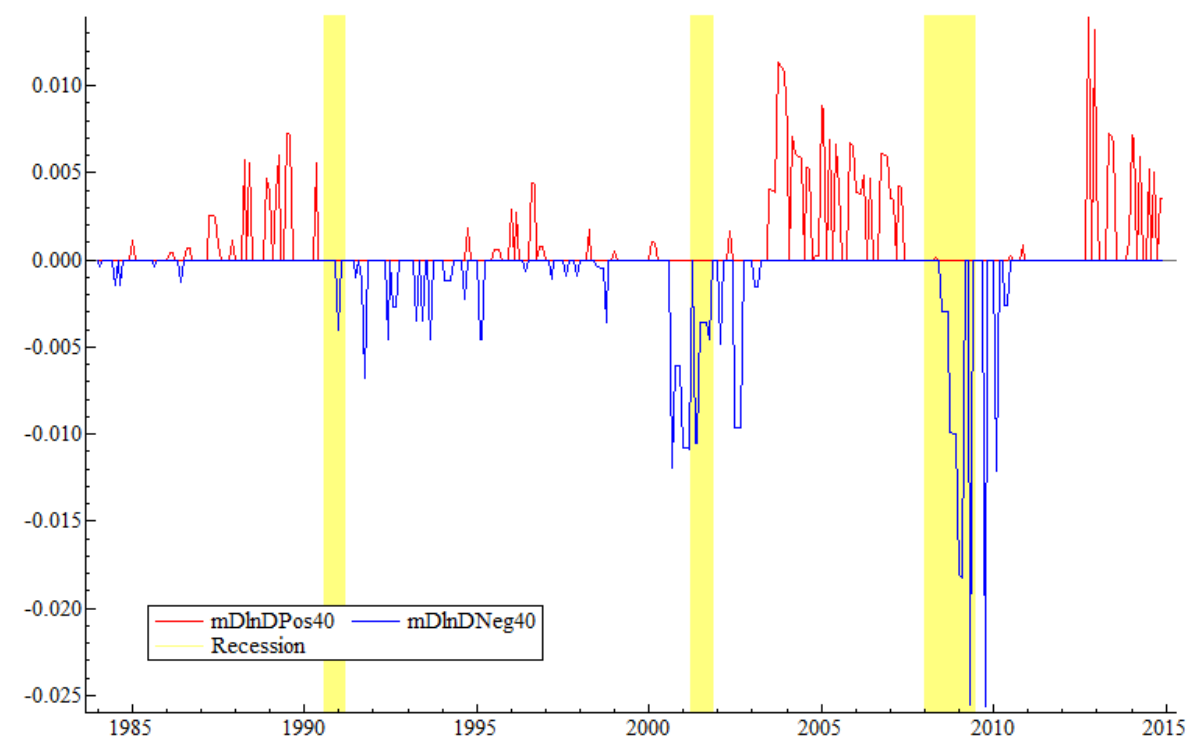


Figure 6: Recession dates and interest rates interacted with a 40th percentile threshold for optimism and pessimism

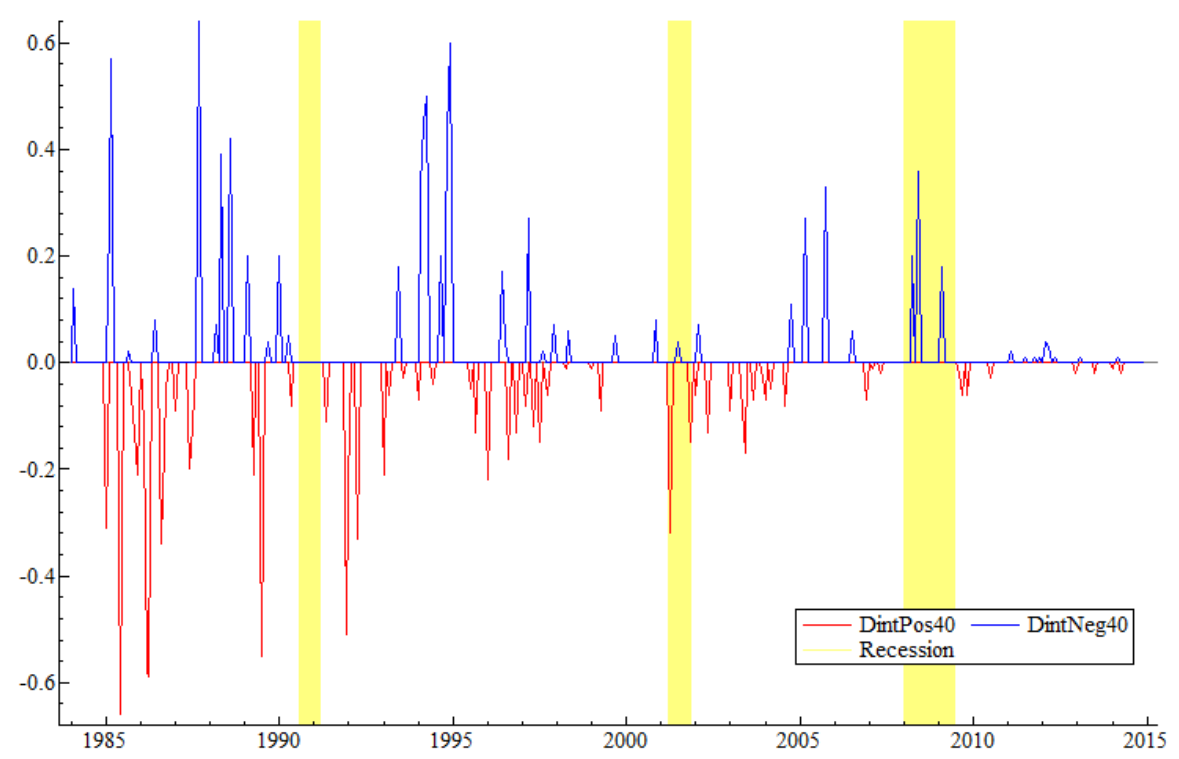

There is some correspondence between our interaction terms and the state of the economy. For dividends, positive news and positive sentiment is primarily observed in expansions, and the negative news and pessimism is proximate to recessions. Interest-rate interactions display less regularity. However, the pattern seems to be that these interactions are generally set to zero during recessions, because the falling rates tend to conflict with the pessimistic market sentiment. Moreover, Figures 5 and 6 illustrate that this connection between our interaction variables and the state of the economy varies erratically, in terms of both timing and magnitude.

We further guard against endogeneity by extracting the systematic correlation between sentiment and the business cycle. This orthogonalization of sentiment is analogous to the approaches in Baker and Wurgler (2006) and Hilliard, Narayanasamy, and Zhang (2019). More specifically, we regress our WSJ sentiment measure on an $\mathrm{AR}(2)$ specification for the monthly annualized rate of growth in industrial production. Further lags were found to be insignificant and the monthly change provided 
a better model fit than the year-on-year growth rate. ${ }^{18}$

Table 4: Regressions of Sentiment on Industrial Production

\begin{tabular}{l|cc}
\hline \hline & y-o-y & m-o-m \\
\hline cons. & -0.279 & -0.286 \\
& {$[-27.28]$} & {$[-30.92]$} \\
IP $_{t}$ & 0.018 & 0.002 \\
& {$[2.83]$} & {$[3.36]$} \\
IP $_{t-1}$ & -0.006 & 0.001 \\
& {$[-0.79]$} & {$[1.82]$} \\
IP $_{t-2}$ & -0.011 & 0.001 \\
& {$[-1.57]$} & {$[2.12]$} \\
Adj. R & 0.029 & 0.052
\end{tabular}

Caption: The y-o-y column uses the year-over-year growth in Industrial Production. The first m-o-m column uses the monthly annualized growth rate. The last column regresses monthly IP growth on sentiment. Newey-West heteroskedasticity and auto-correlation (HAC) robust t-values are displayed in brackets underneath the coefficient estimates.

Table 4 shows that fluctuations in industrial production are a significant predictor of sentiment. However, the goodness of fit is only about $5 \%$, indicating that much of the variation in sentiment is unexplained. We then save the residuals from this regression as our measure of the orthogonalized sentiment (unexplained by fluctuations in industrial production). In Table 5, we show that the main conclusions are robust to using this orthogonalized measure. Only in the model with a 40th percentile threshold do the dividend interactions become less significant. This suggests that it is the more extreme sentiment which may be providing additional information.

The significance of our orthogonalized measure suggests that sentiment is adding

\footnotetext{
${ }^{18}$ We also regressed sentiment on our measures of dividend and interest-rate news. Dividends were highly insignificant $(|t|<0.5)$, and interest rates were significant with the "wrong" sign. The positive correlation between sentiment and interest rates could be interpreted as reverse causation: optimism has caused rising interest rates, rather than rising interest rates leading to an improved outlook for stocks. For this reason, we rely on the orthogonalization with industrial production.
} 
information beyond contemporaneous fluctuations in the economy. This corroborates the arguments of Shiller (2019) and Akerlof and Snower (2016) that textual analysis of market narratives can capture valuable information about non-fundamental considerations.

Table 5: Forecasts of returns with mean dividend growth and orthogonal sentiment

\begin{tabular}{|c|c|c|c|c|}
\hline Percentile & & 15 th & 25 th & 40th \\
\hline cons. & $\begin{array}{l}3.041 \\
{[4.26]}\end{array}$ & $\begin{array}{c}3.532 \\
{[4.67]}\end{array}$ & $\begin{array}{c}3.385 \\
{[4.47]}\end{array}$ & $\begin{array}{c}3.546 \\
{[5.01]}\end{array}$ \\
\hline $\operatorname{AR}(1)$ & $\begin{array}{l}0.891 \\
{[19.02]}\end{array}$ & $\begin{array}{l}0.894 \\
{[18.11]}\end{array}$ & $\begin{array}{l}0.876 \\
{[17.43]}\end{array}$ & $\begin{array}{l}0.879 \\
{[17.77]}\end{array}$ \\
\hline $\operatorname{AR}(2)$ & $\begin{array}{c}-0.085 \\
{[-1.84]}\end{array}$ & $\begin{array}{c}-0.114 \\
{[-2.40]}\end{array}$ & $\begin{array}{c}-0.101 \\
{[-2.10]}\end{array}$ & $\begin{array}{c}-0.093 \\
{[-1.93]}\end{array}$ \\
\hline$\Delta d_{t}^{d m}$ & $\begin{array}{c}-11.393 \\
{[-0.20]}\end{array}$ & $\begin{array}{c}-78.683 \\
{[-1.44]}\end{array}$ & $\begin{array}{c}-99.827 \\
{[-1.88]}\end{array}$ & $\begin{array}{c}-79.142 \\
{[-1.26]}\end{array}$ \\
\hline$\Delta i_{t}$ & $\begin{array}{c}-1.597 \\
{[-0.70]}\end{array}$ & $\begin{array}{c}-0.622 \\
{[-1.14]}\end{array}$ & $\begin{array}{l}0.298 \\
{[0.111]}\end{array}$ & $\begin{array}{l}1.401 \\
{[0.48]}\end{array}$ \\
\hline$\Delta d_{t}^{d m} \cdot S_{\perp t}^{+}$ & & $\begin{array}{c}788.190 \\
{[3.48]}\end{array}$ & 712.782 & $\begin{array}{c}264.123 \\
{[1.48]}\end{array}$ \\
\hline$\Delta d_{t}^{d m} \cdot S_{\perp t}^{-}$ & & $\begin{array}{c}758.474 \\
{[2.70]}\end{array}$ & $\begin{array}{c}489.726 \\
{[1.84]}\end{array}$ & $\begin{array}{c}273.854 \\
{[1.51]}\end{array}$ \\
\hline$\Delta i_{t} \cdot S_{\perp t}^{+}$ & & $\begin{array}{c}-1.150 \\
{[-0.10]}\end{array}$ & -11.444 & $\begin{array}{c}-8.956 \\
{[-1.31]}\end{array}$ \\
\hline$\Delta i_{t} \cdot S_{\perp t}^{-}$ & & $\begin{array}{c}-22.541 \\
{[-4.04]}\end{array}$ & -20.253 & $-{ }_{[-2.81]}^{-16.616}$ \\
\hline $\operatorname{Adj} . \mathrm{R}^{2}$ & 0.671 & 0.686 & 0.689 & 0.681 \\
\hline
\end{tabular}

Caption: Newey-West heteroskedasticity and auto-correlation (HAC) robust $t$-values are displayed in brackets underneath the coefficient estimates.

\section{Structural Change}

Our finding of a significant interaction between sentiment and fundamentals suggests that fundamental models, absent this interaction, would undergo structural change. For example, the effect of dividend growth should be higher during periods when sentiment is optimistic.

However, in a misspecified model where sentiment is omitted, this could manifest as a rising parameter on dividend growth during optimistic periods. Indeed, numerous studies have found that models of stock returns undergo significant para- 
meter instability. ${ }^{19}$

However, we find that when breaks in the parameters arise from the influence of sentiment on the news about fundamentals, it cannot be detected through traditional tests for structural change. For example, as illustrated in Figure 7, the Chow (1960) breakpoint test and one-step forecast tests fail to detect structural change in the linear model, despite the fact that we previously observed a significant, time-varying effect for dividends and interest rates when sentiment was reinforcing.

Figure 7 shows that, although the structural change in how dividend and interestrate news affects returns is evident in Tables 1-3, standard tests have difficulty detecting this change. This suggests that, as Fama (1998) argued, market sentiment has a highly irregular, time-varying influence on how participants forecast returns in terms of fundamentals. However, in contrast to a more persistent form of structural change, this structural change is not detected because the sentiment interactions fluctuate too erratically between non-zero and zero values.

\footnotetext{
${ }^{19}$ Structural change in how fundamentals drive ex post returns has been documented in many studies, including Pastor and Stambaugh (2001), Pettennuzzo and Timmermann (2011), Rapach and Wohar (2006), Paye and Timmermann (2006), Ang and Timmermann (2012), and Mangee (2016). Frydman and Stillwagon (2018) find structural breaks in the relationship between survey measures of ex ante returns and fundamentals.
} 
Figure 7: Chow break-point and Chow forecast test for the forecasted returns model
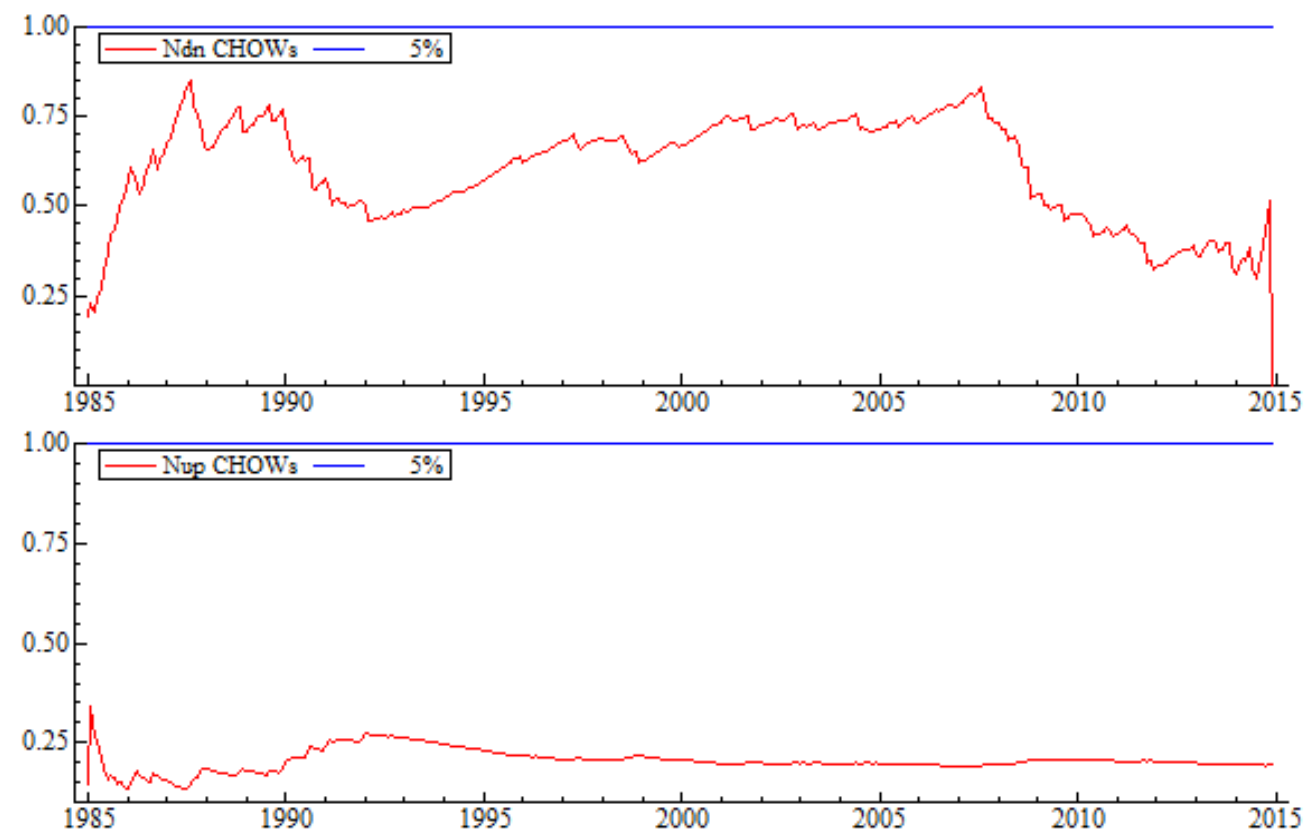

Figure 8 illustrates the estimated effect when dividend news fluctuates rapidly in our empirical model featuring the sentiment interactions. These results correspond to the model in column 4 of Table 1, though they are representative of the other models with interactions. There are sudden and transitory spikes where dividends have a positive coefficient (in red) when positive dividend news coincides with optimism. There is also a positive coefficient of a different magnitude (in blue) when negative dividend news coincides with pessimism, again occurring at irregular and short-lived intervals. When sentiment is neutral or conflicting, the effect of dividend news appears negligible (statistically insignificant). 
Figure 8: Estimated coefficient on dividend news over time

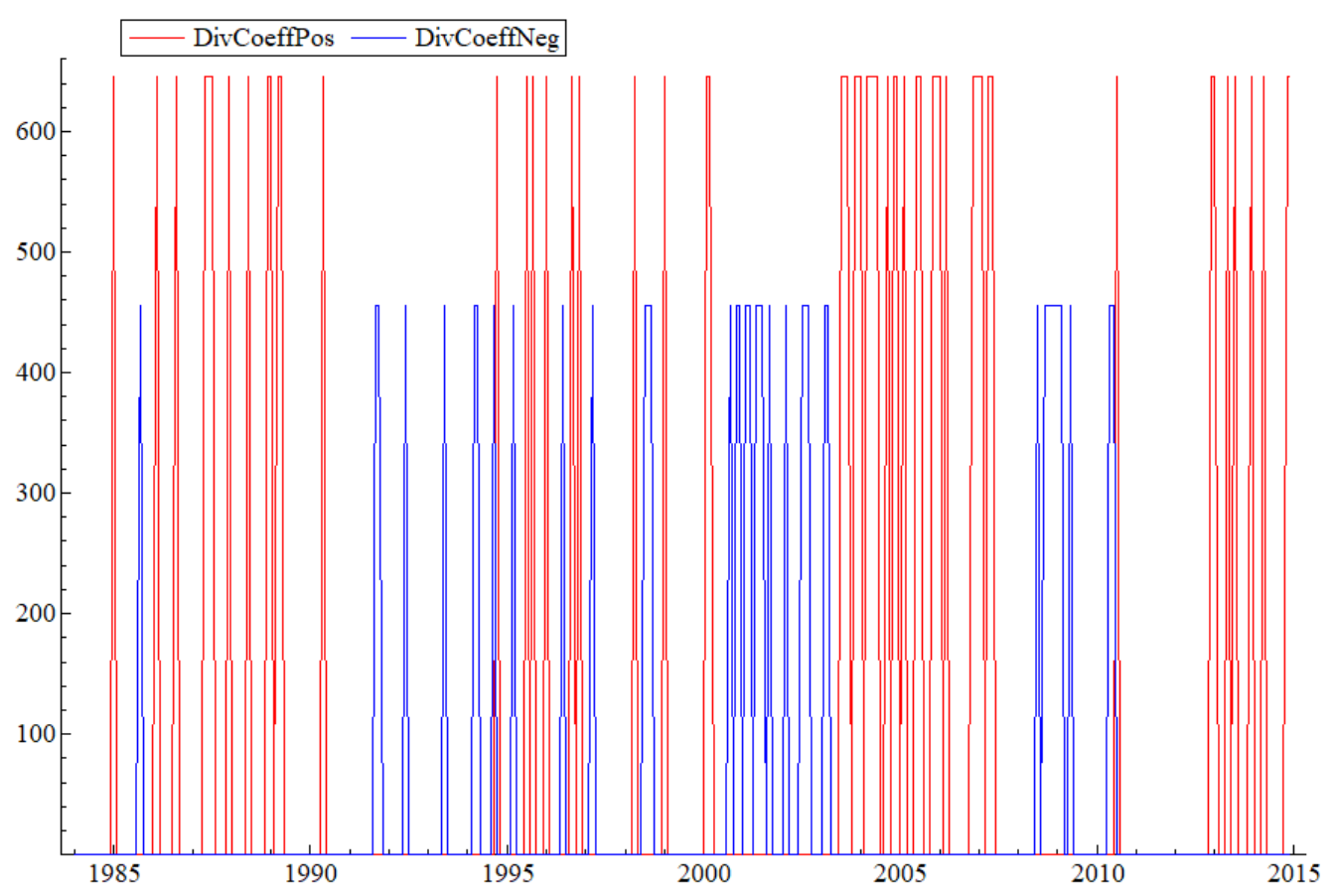

As we report in the Appendix, although, absent the interactions, we cannot detect the changing effect of fundamentals for the models using ex ante returns, we do find significant time-variation in the models of ex post returns as illustrated in Figure 9. This may suggest that much of the structural change observed in prior studies stems from a time-varying, though persistent, divergence between expected and ex post returns. This is consistent with the many studies which reject REH on the basis of survey data. ${ }^{20}$ This highlights the importance of testing models with

\footnotetext{
${ }^{20}$ There is a long literature in the foreign exchange market rejecting REH in survey data. See Stillwagon (2014) and references therein. Coibion and Gorodnichenko (2015) similarly reject full information REH for household and professional inflation expectations.
} 
survey data (i.e., without the assumption of white noise forecast errors). ${ }^{21}$

Figure 9: Chow break-point and Chow forecast test for the ex post returns model
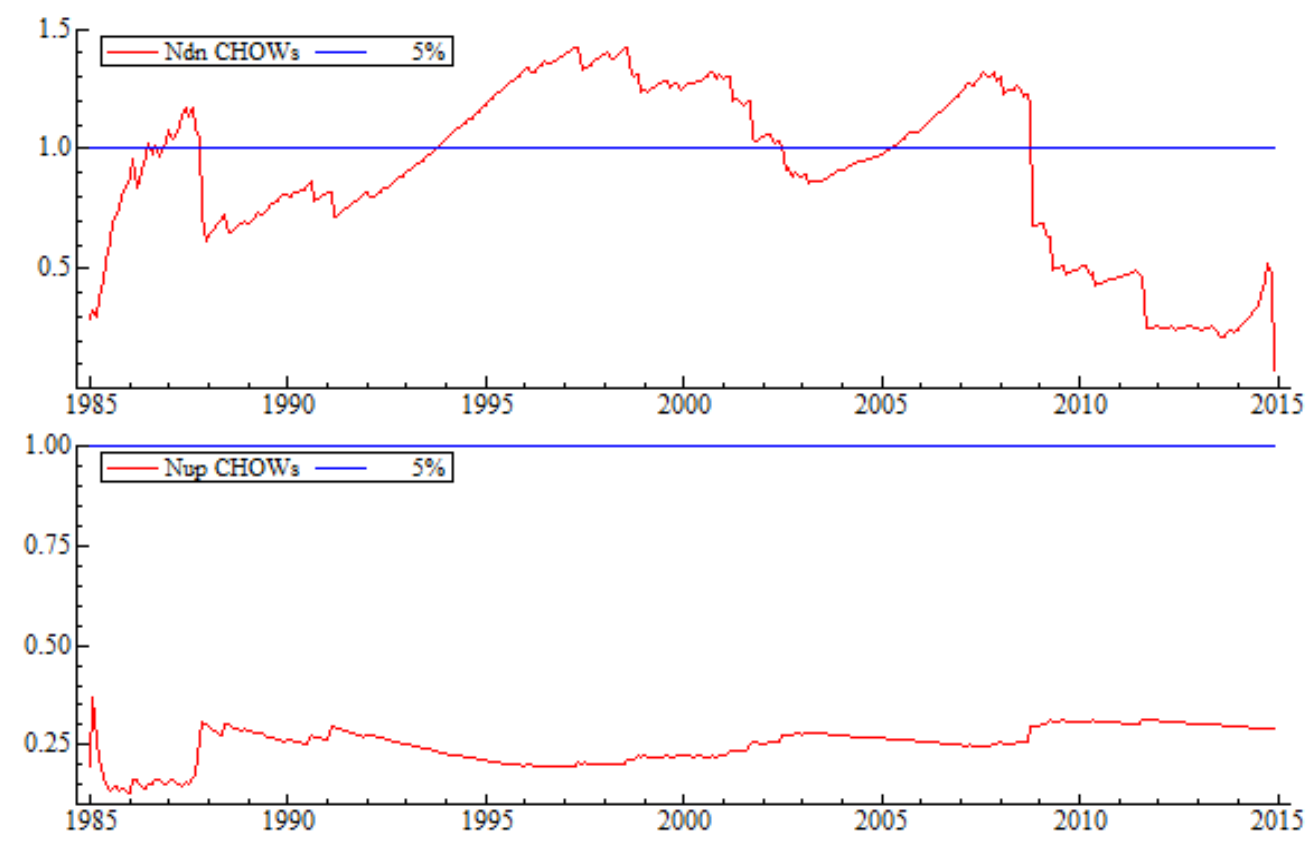

\section{Concluding Remarks}

Our finding that market sentiment influences how participants interpret fundamentals is inconsistent with REH's prediction that forecasts are driven solely by fundamentals. The empirical relevance of market sentiment is consistent with behavioralfinance researchers' findings that non-fundamental factors influence forecasts of stock returns. However, our finding that market sentiment's influence is highly irregular, in terms of both timing and magnitude, appears to be inconsistent with behavioral models' formalization of this influence with a stochastic process.

To formalize our finding with a stochastic process, as the typical behavioral-

\footnotetext{
${ }^{21}$ The ex post model is not rejected however according to the one-step-ahead Chow forecast test, where the model is allowed to update recursively. By contrast, the breakpoint Chow test examines parameter instability for each recursive sub-sample relative to the full sample.
} 
finance model would do, requires that market sentiment's influence on participants' forecasts of stock returns changes at times and in ways that can be specified with a probabilistic rule, such as Markov switching. Though conceivable, the erratic timing and magnitude of structural change arising from market sentiment, which we reported in the preceding section, seem difficult to approximate with such rules on the basis of historical data, let alone represent ex ante over an indefinite future. ${ }^{22}$

It seems plausible that sentiment proxies for a broad array of factors that characterize how participants interpret the state of the economy at any point in time and how this state might change over time. Some of these factors are, at least in part, non-repetitive, and thus there are no past data that could have characterized their effects on the change in economic outcomes, and thus stock returns, with a probabilistic rule ex ante. ${ }^{23}$

This interpretation of structural change in how market sentiment influences stock returns is consistent with a number of earlier studies that related change in the process driving these returns to historical events that are at least in part unique. ${ }^{24}$

Recognizing that market participants face so-called Knightian uncertainty, which, by definition, cannot be represented with a stochastic process, is increasingly viewed as crucial to remedying the difficulties inherent in specifying how market outcomes unfold over time with a probabilistic rule. For example, in his Nobel lecture, Hansen (2013, p. 399) argues that REH models "miss something essential: [Knightian] uncertainty [arising from] ambiguity about which is the correct model" of the process driving aggregate outcomes.

Frydman et al. (2019) argue that, faced with ambiguity, participants rely on

\footnotetext{
${ }^{22}$ Stillwagon and Sullivan (2019) find that while a Markov switching model approximates the exchange-rate process within sample, it is difficult to ascertain the number of states required for such an approximation, particularly out of sample. Moreover, Stillwagon and Sullivan demonstrate that the Markov switching model involving the best-performing number of regimes ex post, which gives the model a very favorable bias, could not outperform a random walk out of sample.

${ }^{23}$ Hendry has pioneered econometric studies focusing on the inherent difficulties in modeling structural change with probabilistic rules. In a series of papers and books, he has demonstrated not only that macroeconomic models experience structural breaks, but also that these breaks are often triggered by historical events. See Hendry and Doornik (2014), Hendry (2018), and references therein.

${ }^{24}$ For econometric evidence, see Ang and Timmermann (2012) and references therein. Frydman et al. (2015) provide descriptive evidence that $20 \%$ of events that triggered movements in US stock prices between 1993 and 2009 were, at least in part, non-repetitive.
} 
non-fundamental factors, such as market sentiment, to select the weights that they attach to news about fundamentals in forecasting stock returns. Our empirical findings are supportive of these implications of Knightian uncertainty and the model ambiguity that it engenders. However, much work remains to be done to establish the theoretical foundations for the empirical specifications that we relied on here, as well as to corroborate our findings in other markets and/or other sample periods.

\section{References}

[1] Akerlof, G.A., Snower, D.J., 2016. Bread and bullets. Journal of Economic Behavior \& Organization 126, 58-71.

[2] Andersen, Torben G., Bollerslev, T., Diebold, F.X., Vega, C., 2007. Real-time price discovery in global stock, bond and foreign exchange markets." Journal of International Economics 73, 251-277.

[3] Ang, A., Bekaert, G., 2006. Stock return predictability: Is it there? The Review of Financial Studies 20, 651-707.

[4] Ang, A., Timmermann, A., 2012. Regime changes and financial markets. Annual Review of Financial Economics 4, 313-327.

[5] Baker, M., Wurgler, J., 2006. Investor sentiment and the cross-section of stock returns. Journal of Finance 61, 1645-1680.

[6] Barberis, N.C., Shleifer, A., Vishny, R., 1998. A model of investor sentiment. Journal of Financial Economics 49, 307-343.

[7] Barsky, R.B., De Long, J.B., 1993. Why does the stock market fluctuate?" Quarterly Journal of Economics 108, 291-311.

[8] Castle, J., Doornik, J., Hendry, D., Pretis, F., 2015. Detecting location shifts during model selection by step-indicator saturation. Econometrics 3, 240-264.

[9] Chan, W.S., 2003. Stock price reaction to news and no-news: Drift and reversal after headlines. Journal of Financial Economics 70, 223-260.

[10] Chopra, N., Lakonishok, J., Ritter, J., 1992. Measuring abnormal performance: do stocks overreact? Journal of Financial Economics 31, 235-268.

[11] Chow, G.C., 1960. Test of equality between sets of coefficients in two linear regressions. Econometrica 28, 591-605. 
[12] Coibion, O., Gorodnichenko, Y., 2012. What can survey forecasts tell us about information rigidities?. Journal of Political Economy 120, 116-159.

[13] Coibion, O., Gorodnichenko, Y., 2015. Information rigidity and the expectations formation process: A simple framework and new facts. American Economic Review 105, 2644-2678.

[14] Cutler, D., Poterba, J., Summers, L., 1991. Speculative Dynamics. Review of Economic Studies 58, 529-546.

[15] De Bondt, W.,Thaler, R., 1985. Does the stock market overreact? Journal of Finance 40, 793-808.

[16] Doornik, J.A., 2009. Autometrics. in Castle, J.L. and Shephard, N., The Methodology and Practice of Econometrics, Oxford University Press.

[17] Fama,E.F., 1998. Market efficiency, long-term returns and behavioral finance. Journal of Financial Economics 49, 283-306.

[18] Fama, E.F., French, K. 1992. The cross-section of expected stock returns. Journal of Finance 47, 427-465.

[19] Frydman, R., Goldberg, M.D., Mangee, N., 2015. Knightian uncertainty and stock-price movements: Why the REH present-value model failed empirically. Economics: The Open-Access, Open-Assessment E-Journal 9, 1-50.

[20] Frydman, R., Johansen, S., Rahbek, A., Tabor, M.N., 2019. The knightian uncertainty hypothesis: Unforeseeable change and Muth's consistency constraint in modeling aggregate outcomes. INET working paper.

[21] Frydman, R., Stillwagon, J.R. 2018. Fundamental factors and extrapolation in stock-market expectations: the central role of structural change. Journal of Economic Behavior \& Organization 148, 189-198.

[22] Garcia, D., 2013. Sentiment during recessions. Journal of Finance 68, 12671300.

[23] Greenwood, R., Shleifer, A., 2014. Expectations of returns and expected returns. Review of Financial Studies 27, 714-746.

[24] Hamilton, J.D., 1988. Rational-expectations econometric analysis of changes in regime: an investigation of the term structure of interest rates. Journal of Economics Dynamics and Control 12, 385-423. 
[25] Hamilton, J. D., 2008. Regime-wwitching models. In Durlauf, S., Blume, L. (eds.), New Palgrave Dictionary of Economics. 2nd edition, Palgrave McMillan Ltd.

[26] Hansen, L.P., 2013. Uncertainty outside and inside economic models. The Nobel Prize Lecture. The Nobel Foundation.

[27] Hendry, D.F., 2018. Deciding between alternative approaches in macroeconomics. International Journal of Forecasting 34, 119-135.

[28] Hendry, D.F., Johansen, S., Santos, C., 2008. Automatic selection of indicators in a fully saturated regression. Computational Statistics 23, 317-335.

[29] Hendry, D.F., Krolzig, H.-M., 2005. The properties of automatic GETS modeling. Economic Journal 115, C32-C61.

[30] Hilliard, J., Jahera, J., Zhang, H., 2019. The US financial crisis and corporate dividend reactions: for better or for worse?. Review of Quantitative Finance and Accounting, 53(4), 1165-1193.

[31] Hilliard, J., Narayanasamy, A., Zhang, S. , 2019. The role of market sentiment in asset allocations and stock returns. Journal of Behavioral Finance, 1-19.

[32] La Porta, R., 1996. Expectations and the cross-section of returns. Journal of Finance 51, 1715-1742.

[33] Lakonishok, J., Shleifer, A., Vishny, R., 1994. Contrarian investment, extrapolation, and risk. Journal of Finance 49, 1541-1578.

[34] Loughran, T., McDonald, B., 2011. When is a liability not a liability? Textual analysis, dictionaries and 10-Ks. Journal of Finance 66, 35-65.

[35] Mangee, N., 2019. Stock returns and the tone of marketplace information: does context matter?. Journal of Behavioral Finance. forthcoming.

[36] Mangee, N., 2017. New evidence on psychology and stock returns. Journal of Behavioral Finance 18, 417-26.

[37] Mangee, N., 2016. Can structural change explain the Meese-Rogoff puzzle?: an application to the stock market. Journal of Economics and Finance 40, 211-234.

[38] Mankiw, N.G., Reis, R., 2002. Sticky information versus sticky prices: a proposal to replace the New Keynesian Phillips Curve. The Quarterly Journal of Economics 117, 1295-1328. 
[39] Mehra, R., Prescott, E.C. 1985. The equity premium: A puzzle." Journal of Monetary Economics 15, 145-161.

[40] Mian, G.M., Sankaraguruswamy, S. 2012. Investor sentiment and stock market response to earnings news. The Accounting Review 87, 1357-1384.

[41] Newey, W., West, K., 1987. A simple, positive-definite heteroskedasticity and autocorrelation consistent covariance matrix. Econometrica 55, 703-708.

[42] Pastor, L., Stambaugh, R.F, 2001. The equity premium and structural breaks. Journal of Finance 56, 1207-1239.

[43] Paye, B.S., Timmermann, A., 2006. Instability of return prediction models. Journal of Empirical Finance 13, 274-315.

[44] Pearce, D.K., Roley, V.V., 1985. Stock prices and economic news. Journal of Business 58, 49-67.

[45] Pettenuzzo, D, Timmermann, A., 2011. Predictability of stock returns and asset allocations under structural breaks. Journal of Econometrics 164, 60-78.

[46] Rapach, D.E., Wohar, M.E., 2006. Structural breaks and predictive regression models of aggregate U.S. stock returns. Journal of Financial Econometrics 4, 238-274.

[47] Shiller, R.J., 2005, Irrational Exuberance, second edition. Princeton University Press.

[48] Shiller, R.J., 2017. Narrative economics. American Economic Review 107, 967-1004.

[49] Shiller, R.J., 2019. Narrative Economics: How Stories Go Viral and Drive Major Economic Events. Princeton University Press.

[50] Stillwagon, J.R., 2014. Reexamining what survey data say about currency risk and irrationality using the cointegrated VAR. Economics Bulletin 34, 16311643.

[51] Stillwagon, J.R., Sullivan, P., 2019. Markov switching in exchange rate models: will more regimes help?. Empirical Economics forthcoming.

[52] Tetlock, P.C., 2007. Giving Content to Investor Sentiment: the Role of Media in the Stock Market. Journal of Finance 62, 1139-1168.

[53] Tetlock, P.C., Saar-Tsechansky, M., Macskassy, S., 2008. More than words: Quantifying language to measure firms' fundamentals. The Journal of Finance 
63, 1437-1467.

[54] Welch, I., Goyal, A., 2008. A comprehensive look at the empirical performance of equity premium prediction. Review of Financial Studies 21, 14551508. 


\section{Appendix}

\subsection{Details on Outlier/Break Detection for Table 3}

Table 3 includes step indicator saturation (SIS) to ensure that the observed correlations are not solely artifacts of an unmodeled shift in the dependent variable. These shifts could be driven by announcements from policymakers or geopolitical events which are difficult to incorporate into a quantitative model. Similarly, they could be driven by expected changes in fundamentals which have yet to materialize. Our sentiment measure should capture much of these effects, but SIS can also control for significant shifts in omitted variables more generally. The indicator saturation also ensures a well-specified statistical model valid for conducting inference. The algorithm ensures that model reduction does not produce residual misspecification significant at the $1 \%$ level. Hendry and Krolzig (2005) suggest using the $1 \%$ level, as using a $5 \%$ level would result in rejecting a good model based on one of the five tests (serial correlation, heteroskedasticity, ARCH normality, or RESET) about $25 \%$ of the time, which is deemed too high of a type I error.

We again select SIS, and now also impulse indicator saturation (IIS), at the $0.1 \%$ significance level, so only one in a thousand would be retained by chance. The price of this robust estimation is a loss in efficiency, although we still attain many significant effects in Table 3. The estimates below show the timing of the breaks for the respective samples, and the associated coefficient and t-value in brackets. The coefficient estimates are displayed after the model selection bias-correction of Hendry and Krolzig (2005).

Indicators for the $15^{\text {th }}$ percentile model: Step indicators - 1989(12): 8.214 [3.05]; 1991(01): -19.792 [-3.55]; 1991(04): 13.956 [2.72]; 1995(11): -5.222 [3.69]

Indicators for the $25^{\text {th }}$ percentile model: Step indicators - 1989(12): 7.922 [2.96] ; 1991(01): -20.046 [ -3.62]; 1991(04): 13.670 [ 2.66]; 1994(12): -4.217 [-2.81]

Indicators for the $40^{\text {th }}$ percentile model: Impulse indicators - 1984(08): 24.210 
[2.81] ; 1988(11): -23.507 [-2.73]; Step indicators - 1989(12): 7.1879 [2.69] ; 1991(01):-32.455 [-3.67]; 1991(02): 22.394 [2.81];

The consistent theme is that there are breaks in 1989(12), 1991(01), and 1991(04). In terms of the estimates, after 1989(12) the expected return falls, exogenous to our model. The expected return, all else equal in the model, is then higher after 1991(1) for three months, and then reverts back to approximately its pre-1989 level. In the $15^{\text {th }}$ and $25^{\text {th }}$ percentile models, the expected return rises slightly after the mid 1990's as well. The $40^{\text {th }}$ percentile model also possesses two outliers in 1984(08) and 1988(11).

\subsection{Additive Sentiment in Models of Forecasted Returns}

Table 6 demonstrates that the inclusion of the sentiment measure in the model of forecasted returns renders the entire effect of fundamentals insignificant.

Table 6: forecasted returns with mean dividend growth and additive sentiment

\begin{tabular}{|c|c|c|c|c|}
\hline Percentile & & 15th & 25 th & 40th \\
\hline cons. & $\begin{array}{c}3.041 \\
{[4.26]}\end{array}$ & $\begin{array}{l}11.398 \\
{[6.12]}\end{array}$ & $\underset{[5.62]}{10.978}$ & ${ }_{[7.28]}^{12.483}$ \\
\hline $\mathrm{AR}(1)$ & $\begin{array}{l}0.891 \\
{[19.02]}\end{array}$ & $\begin{array}{l}0.878 \\
{[18.31]}\end{array}$ & $\begin{array}{l}0.873 \\
{[18.34]}\end{array}$ & $\begin{array}{l}0.880 \\
{[18.44]}\end{array}$ \\
\hline $\mathrm{AR}(2)$ & $\begin{array}{c}-0.085 \\
{[-1.84]}\end{array}$ & $\begin{array}{c}-0.107 \\
{[-2.34]}\end{array}$ & $\begin{array}{c}-0.107 \\
{[-2.36]}\end{array}$ & $\begin{array}{l}-0.107 \\
{[-2.35]}\end{array}$ \\
\hline$\Delta d_{t}^{d m}$ & $\begin{array}{l}-11.393 \\
{[-0.20]}\end{array}$ & $\underset{[0.22]}{13.564}$ & $\underset{[0.17]}{10.866}$ & $\begin{array}{c}88.183 \\
{[0.99]}\end{array}$ \\
\hline$\Delta i_{t}$ & $\begin{array}{c}-1.597 \\
{[-0.70]}\end{array}$ & $\begin{array}{c}-4.112 \\
{[-1.91]}\end{array}$ & $\begin{array}{c}-3.858 \\
{[-1.61]}\end{array}$ & $\begin{array}{c}-3.936 \\
{[-1.49]}\end{array}$ \\
\hline$\Delta d_{t}^{d m} \cdot S_{t}^{+}$ & & $\begin{array}{l}-27.501 \\
{[-0.11]}\end{array}$ & $\underset{[0.91]}{228.804}$ & $-\underset{[-1.27]}{248.825}$ \\
\hline$\Delta d_{t}^{d m} \cdot S_{t}^{-}$ & & $\begin{array}{c}52.780 \\
{[0.20]}\end{array}$ & $\begin{array}{l}-97.218 \\
{[-0.62]}\end{array}$ & $-\underset{[-0.96]}{-146.163}$ \\
\hline$\Delta i_{t} \cdot S_{t}^{+}$ & & 12.411 & 7.255 & $\begin{array}{c}6.037 \\
{[0.89]}\end{array}$ \\
\hline$\Delta i_{t} \cdot S_{t}^{-}$ & & $\begin{array}{l}-16.116 \\
{[-2.96]}\end{array}$ & $\begin{array}{l}-11.233 \\
{[-2.33]}\end{array}$ & $\begin{array}{c}-8.523 \\
{[-1.60]}\end{array}$ \\
\hline Sent $_{t}$ & & $\begin{array}{c}27.955 \\
{[5.06]}\end{array}$ & $\begin{array}{c}26.719 \\
{[4.56]}\end{array}$ & $\begin{array}{c}31.067 \\
{[6.32]}\end{array}$ \\
\hline Adj. $R^{2}$ & 0.671 & 0.705 & 0.706 & 0.706 \\
\hline
\end{tabular}

Caption: Newey-West heteroskedasticity and auto-correlation (HAC) robust tvalues are displayed in brackets underneath the coefficient estimates. 


\subsection{Models of Ex Post Returns}

We have also investigated the effects of fundamentals and interaction terms in driving ex post returns. Tables 7 and 8 replicate the results of Tables 1 and 2 for $e x$ post returns.

Again, we observe no significant effects for fundamentals without interactions, but significant effects for both dividends and interest-rate news for each threshold examined. The models for ex post returns have much lower model fit, as one might expect given the added noise of forecast errors, but the improvement from the inclusion of the interaction terms is greater in absolute and percentage terms than in the models of forecasted returns.

Table 7: Ex post returns with mean dividend growth

\begin{tabular}{|c|c|c|c|c|}
\hline Percentile & & 15 th & 25 th & 40th \\
\hline cons. & $\begin{array}{l}0.008 \\
{[4.76]}\end{array}$ & $\begin{array}{c}0.008 \\
{[4.76]}\end{array}$ & $\begin{array}{c}0.007 \\
{[4.40]}\end{array}$ & $\begin{array}{c}0.008 \\
{[4.33]}\end{array}$ \\
\hline $\operatorname{AR}(1)$ & $\begin{array}{c}0.277 \\
{[4.16]}\end{array}$ & $\begin{array}{l}0.217 \\
{[3.22]}\end{array}$ & $\begin{array}{c}0.269 \\
{[3.86]}\end{array}$ & $\begin{array}{c}0.252 \\
{[3.69]}\end{array}$ \\
\hline $\operatorname{AR}(2)$ & $\begin{array}{c}-0.068 \\
{[-1.36]}\end{array}$ & $\begin{array}{c}-0.159 \\
{[-2.92]}\end{array}$ & $\begin{array}{c}-0.153 \\
{[-2.71]}\end{array}$ & $\begin{array}{c}-0.131 \\
{[-2.26]}\end{array}$ \\
\hline$\Delta d_{t}^{d m}$ & $\begin{array}{c}0.003 \\
{[0.01]}\end{array}$ & $\begin{array}{c}-0.614 \\
{[-2.57]}\end{array}$ & $\begin{array}{c}-0.905 \\
{[-4.03]}\end{array}$ & $\begin{array}{c}-0.902 \\
{[-3.78]}\end{array}$ \\
\hline$\Delta i_{t}$ & $\begin{array}{c}0.004 \\
{[0.48]}\end{array}$ & $\begin{array}{c}0.004 \\
{[0.43]}\end{array}$ & $\begin{array}{c}0.011 \\
{[1.13]}\end{array}$ & $\begin{array}{c}0.017 \\
{[1.51]}\end{array}$ \\
\hline$\Delta d_{t}^{d m} \cdot S_{t}^{+}$ & & $\begin{array}{c}2.345 \\
{[2.50]}\end{array}$ & $\begin{array}{c}2.657 \\
{[4.13]}\end{array}$ & $\begin{array}{c}1.351 \\
{[2.45]}\end{array}$ \\
\hline$\Delta d_{t}^{d m} \cdot S_{t}^{-}$ & & $\begin{array}{c}7.493 \\
{[4.51]}\end{array}$ & $\begin{array}{l}4.180 \\
{[3.42]}\end{array}$ & $\begin{array}{c}3.197 \\
{[3.03]}\end{array}$ \\
\hline$\Delta i_{t} \cdot S_{t}^{+}$ & & $\begin{array}{c}-0.104 \\
{[-1.85]}\end{array}$ & $\begin{array}{c}-0.082 \\
{[-2.56]}\end{array}$ & $\begin{array}{c}-0.064 \\
{[-3.42]}\end{array}$ \\
\hline$\Delta i_{t} \cdot S_{t}^{-}$ & & $\begin{array}{c}-0.081 \\
{[-6.16]}\end{array}$ & $\begin{array}{c}-0.064 \\
{[-3.90]}\end{array}$ & $\begin{array}{c}-0.064 \\
{[-3.90]}\end{array}$ \\
\hline Adj. $\mathrm{R}^{2}$ & 0.065 & 0.207 & 0.184 & 0.166 \\
\hline
\end{tabular}

Caption: Newey-West heteroskedasticity and auto-correlation (HAC) robust tvalues are displayed in brackets underneath the coefficient estimates. 
Table 8: Ex post returns with breaks in mean dividend growth

\begin{tabular}{|c|c|c|c|c|}
\hline Percentile & & 15 th & 25 th & 40th \\
\hline cons. & $\begin{array}{c}0.006 \\
{[3.06]}\end{array}$ & $\begin{array}{l}0.007 \\
{[3.88]}\end{array}$ & $\begin{array}{l}0.007 \\
{[3.41]}\end{array}$ & $\begin{array}{l}0.006 \\
{[3.09]}\end{array}$ \\
\hline $\mathrm{AR}(1)$ & $\begin{array}{c}0.277 \\
{[4.13]}\end{array}$ & $\begin{array}{c}0.234 \\
{[3.72]}\end{array}$ & $\begin{array}{c}0.246 \\
{[3.70]}\end{array}$ & $\begin{array}{c}0.218 \\
{[3.69]}\end{array}$ \\
\hline $\operatorname{AR}(2)$ & $\begin{array}{c}-0.067 \\
{[-1.33]}\end{array}$ & $\begin{array}{c}-0.127 \\
{[-2.63]}\end{array}$ & $\begin{array}{c}-0.098 \\
{[-1.87]}\end{array}$ & $\begin{array}{c}-0.087 \\
{[-1.64]}\end{array}$ \\
\hline$\Delta d_{t}^{d m}$ & $\begin{array}{l}-0.131 \\
{[-0.168]}\end{array}$ & $\begin{array}{c}-1.017 \\
{[-1.29]}\end{array}$ & $\begin{array}{c}-0.878 \\
{[-1.04]}\end{array}$ & $\begin{array}{c}-1.128 \\
{[-1.94]}\end{array}$ \\
\hline$\Delta i_{t}$ & $\begin{array}{c}0.004 \\
{[0.51]}\end{array}$ & $\begin{array}{c}0.007 \\
{[0.64]}\end{array}$ & $\begin{array}{c}0.009 \\
{[0.78]}\end{array}$ & $\begin{array}{c}0.024 \\
{[2.02]}\end{array}$ \\
\hline$\Delta d_{t}^{d m} \cdot S_{t}^{+}$ & & $\begin{array}{l}1.523 \\
{[0.75]}\end{array}$ & $\begin{array}{c}3.739 \\
{[2.86]}\end{array}$ & $\begin{array}{l}1.574 \\
{[1.01]}\end{array}$ \\
\hline$\Delta d_{t}^{d m} \cdot S_{t}^{-}$ & & $\begin{array}{l}7.905 \\
{[3.21]}\end{array}$ & $\begin{array}{l}4.267 \\
{[2.31]}\end{array}$ & $\begin{array}{l}4.819 \\
{[2.50]}\end{array}$ \\
\hline$\Delta i_{t} \cdot S_{t}^{+}$ & & $\begin{array}{c}-0.039 \\
{[-1.64]}\end{array}$ & $\begin{array}{c}-0.029 \\
{[-1.20]}\end{array}$ & $\begin{array}{c}-0.058 \\
{[-3.09]}\end{array}$ \\
\hline$\Delta i_{t} \cdot S_{t}^{-}$ & & $\begin{array}{c}-0.019 \\
{[-0.90]}\end{array}$ & $\begin{array}{c}-0.032 \\
{[-1.67]}\end{array}$ & $\begin{array}{c}-0.070 \\
{[-3.60]}\end{array}$ \\
\hline Adj. $\mathrm{R}^{2}$ & 0.065 & 0.117 & 0.092 & 0.133 \\
\hline
\end{tabular}

Caption: Newey-West heteroskedasticity and auto-correlation (HAC) robust tvalues are displayed in brackets underneath the coefficient estimates. 


\subsection{Models with Ex Post Returns and Additive Sentiment}

These models have much lower model fit than those for forecasted returns in Table 1. This is consistent with the difficulties documented in the literature in accounting for ex post returns, which in turn underscores the importance of using survey data in studies of asset markets.

Table 9: Ex post returns with mean dividend growth and additive sentiment

\begin{tabular}{l|cccc} 
Percentile & & 15 th & 25 th & 40 th \\
\hline cons. & 0.006 & 0.049 & 0.049 & 0.053 \\
& {$[2.92]$} & {$[9.04]$} & {$[8.09]$} & {$[9.09]$} \\
AR(1) & 0.277 & 0.187 & 0.223 & 0.220 \\
& {$[4.16]$} & {$[2.72]$} & {$[3.18]$} & {$[3.25]$} \\
AR(2) & -0.068 & -0.179 & -0.168 & -0.146 \\
& {$[-1.36]$} & {$[-3.27]$} & {$[-3.10]$} & {$[-2.68]$} \\
$\Delta d_{t}^{d m}$ & 0.003 & -0.172 & -0.180 & 0.083 \\
& {$[0.01]$} & {$[-0.62]$} & {$[-0.633]$} & {$[0.22]$} \\
$\Delta i_{t}$ & 0.004 & -0.011 & -0.008 & -0.007 \\
& {$[0.48]$} & {$[-1.57]$} & {$[-0.96]$} & {$[-0.83]$} \\
$\Delta d_{t}^{d m} \cdot S_{t}^{+}$ & & -1.308 & -0.836 & -1.774 \\
$\Delta d_{t}^{d m} \cdot S_{t}^{-}$ & & {$[-1.41]$} & {$[-1.03]$} & {$[-2.46]$} \\
$\Delta i_{t} \cdot S_{t}^{+}$ & & 5.149 & 2.271 & 1.272 \\
$\Delta i_{t} \cdot S_{t}^{-}$ & & {$[3.38]$} & {$[2.24]$} & {$[1.65]$} \\
Sent & & 0.031 & -0.002 & -0.005 \\
& & {$[0.712]$} & {$[-0.11]$} & {$[-0.31]$} \\
Adj. R & & -0.016 & -0.007 & -0.009 \\
Caption & & {$[-0.88]$} & {$[-0.46]$} & {$[-0.60]$} \\
& & 0.144 & 0.146 & 0.159 \\
& & {$[7.28]$} & {$[6.78]$} & {$[7.52]$} \\
& & 0.317 & 0.282 & 0.281
\end{tabular}

Caption: Newey-West heteroskedasticity and auto-correlation (HAC) robust tvalues are displayed in brackets underneath the coefficient estimates. 
Table 10: Forecasts of returns with mean dividend growth until the Great Re-

\begin{tabular}{|c|c|c|c|c|}
\hline Percentile & & 15 th & 25 th & 40th \\
\hline cons. & $\begin{array}{l}3.023 \\
{[3.94]}\end{array}$ & $\begin{array}{l}3.131 \\
{[3.99]}\end{array}$ & $\begin{array}{l}3.030 \\
{[3.72]}\end{array}$ & $\begin{array}{c}3.207 \\
{[3.95]}\end{array}$ \\
\hline $\operatorname{AR}(1)$ & $\begin{array}{l}0.887 \\
{[16.04]}\end{array}$ & $\begin{array}{l}0.897 \\
{[15.47]}\end{array}$ & $\begin{array}{l}0.888 \\
{[15.29]}\end{array}$ & $\begin{array}{l}0.886 \\
{[17.42]}\end{array}$ \\
\hline $\mathrm{AR}(2)$ & $\begin{array}{c}-0.098 \\
{[-1.87]}\end{array}$ & $\begin{array}{c}-0.119 \\
{[-2.18]}\end{array}$ & $\begin{array}{c}-0.126 \\
{[-2.36]}\end{array}$ & $\begin{array}{c}-0.121 \\
{[-2.29]}\end{array}$ \\
\hline$\Delta d_{t}^{d m}$ & $\begin{array}{c}-12.891 \\
{[-0.13]}\end{array}$ & $-\frac{178.430}{[-1.63]}$ & $\begin{array}{c}-246.346 \\
{[-1.83]}\end{array}$ & $\begin{array}{c}-252.115 \\
{[-0.79]}\end{array}$ \\
\hline$\Delta i_{t}$ & $\begin{array}{c}-3.372 \\
{[-1.56]}\end{array}$ & $\begin{array}{c}-2.595 \\
{[-1.14]}\end{array}$ & $\begin{array}{c}-2.128 \\
{[-0.88]}\end{array}$ & $\begin{array}{l}-1.750 \\
{[-0.588]}\end{array}$ \\
\hline$\Delta d_{t}^{d m} \cdot S_{t}^{+}$ & & $\begin{array}{c}712.591 \\
{[2.43]}\end{array}$ & $\begin{array}{c}1019.27 \\
{[3.83]}\end{array}$ & $\begin{array}{c}656.022 \\
{[2.41]}\end{array}$ \\
\hline$\Delta d_{t}^{d m} \cdot S_{t}^{-}$ & & $\begin{array}{c}699.769 \\
{[2.75]}\end{array}$ & $\begin{array}{c}207.156 \\
{[0.79]}\end{array}$ & $\begin{array}{c}280.766 \\
{[0.85]}\end{array}$ \\
\hline$\Delta i_{t} \cdot S_{t}^{+}$ & & $\begin{array}{c}-13.195 \\
{[-0.89]}\end{array}$ & $\begin{array}{c}-6.316 \\
{[-0.92]}\end{array}$ & $\begin{array}{c}-3.818 \\
{[-0.56]}\end{array}$ \\
\hline$\Delta i_{t} \cdot S_{t}^{-}$ & & $\begin{array}{c}-27.331 \\
{[-4.23]}\end{array}$ & $\begin{array}{c}-17.347 \\
{[-3.70]}\end{array}$ & $\begin{array}{c}-13.131 \\
{[-2.30]}\end{array}$ \\
\hline Adj. $\mathrm{R}^{2}$ & 0.660 & 0.673 & 0.675 & 0.670 \\
\hline
\end{tabular}

Caption: Newey-West heteroskedasticity and auto-correlation (HAC) robust tvalues are displayed in brackets underneath the coefficient estimates. 